\title{
Article \\ Cellular Localization of Kynurenine 3-Monooxygenase in the Brain: Challenging the Dogma
}

\author{
Korrapati V. Sathyasaikumar ${ }^{1,+}$, Verónica Pérez de la Cruz $^{2,+} \mathbb{D}$, Benjamín Pineda ${ }^{3,+} \mathbb{D}_{\text {, }}$ \\ Gustavo Ignacio Vázquez Cervantes ${ }^{2} \mathbb{D}$, Daniela Ramírez Ortega ${ }^{2} \mathbb{D}$, David W. Donley ${ }^{4}$, Paul L. Severson ${ }^{5}$, \\ Brian L. West ${ }^{5}$ (D), Flaviano Giorgini ${ }^{6}$, Jonathan H. Fox ${ }^{4}$ and Robert Schwarcz ${ }^{1, *(D)}$
}

Citation: Sathyasaikumar, K.V.; Pérez de la Cruz, V.; Pineda, B.; Vázquez Cervantes, G.I.; Ramírez Ortega, D.; Donley, D.W.; Severson, P.L.; West, B.L.; Giorgini, F.; Fox, J.H.; et al. Cellular Localization of Kynurenine 3-Monooxygenase in the Brain: Challenging the Dogma. Antioxidants 2022, 11, 315. https://doi.org/ 10.3390/antiox11020315

Academic Editors: Johanna M. Gostner and Blanca Laffon

Received: 13 January 2022

Accepted: 2 February 2022

Published: 4 February 2022

Publisher's Note: MDPI stays neutral with regard to jurisdictional claims in published maps and institutional affiliations.

Copyright: (C) 2022 by the authors. Licensee MDPI, Basel, Switzerland. This article is an open access article distributed under the terms and conditions of the Creative Commons Attribution (CC BY) license (https:// creativecommons.org/licenses/by/ $4.0 /)$.
1 Maryland Psychiatric Research Center, Department of Psychiatry, University of Maryland School of Medicine, Baltimore, MD 21228, USA; saikumar@som.umaryland.edu

2 Neurobiochemistry and Behavior Laboratory, National Institute of Neurology and Neurosurgery "Manuel Velasco Suárez", Mexico City 14269, Mexico; veped@yahoo.com.mx (V.P.d.1.C.); guigvace@gmail.com (G.I.V.C.); drmz_ortega@hotmail.com (D.R.O.)

3 Neuroimmunology Department, National Institute of Neurology and Neurosurgery "Manuel Velasco Suárez", Mexico City 14269, Mexico; benjamin.pineda@innn.edu.mx

4 Department of Veterinary Sciences, University of Wyoming, Laramie, WY 82071, USA; ddonley@harding.edu (D.W.D.); jfox7@uwyo.edu (J.H.F.)

5 Plexxikon Inc., South San Francisco, CA 94080, USA; seversonpaul@gmail.com (P.L.S.); bwest.cima@gmail.com (B.L.W.)

6 Department of Genetics and Genome Biology, University of Leicester, Leicester LE1 7JA, UK; fg36@le.ac.uk

* Correspondence: rschwarcz@som.umaryland.edu; Tel.: +1-410-402-7635

+ Equal Contribution.

\begin{abstract}
Kynurenine 3-monooxygenase (KMO), a key player in the kynurenine pathway (KP) of tryptophan degradation, regulates the synthesis of the neuroactive metabolites 3-hydroxykynurenine (3-HK) and kynurenic acid (KYNA). KMO activity has been implicated in several major brain diseases including Huntington's disease (HD) and schizophrenia. In the brain, KMO is widely believed to be predominantly localized in microglial cells, but verification in vivo has not been provided so far. Here, we examined KP metabolism in the brain after depleting microglial cells pharmacologically with the colony stimulating factor 1 receptor inhibitor PLX5622. Young adult mice were fed PLX5622 for 21 days and were euthanized either on the next day or after receiving normal chow for an additional 21 days. Expression of microglial marker genes was dramatically reduced on day 22 but had fully recovered by day 43. In both groups, PLX5622 treatment failed to affect Kmo expression, KMO activity or tissue levels of 3-HK and KYNA in the brain. In a parallel experiment, PLX5622 treatment also did not reduce KMO activity, 3-HK and KYNA in the brain of R6/2 mice (a model of HD with activated microglia). Finally, using freshly isolated mouse cells ex vivo, we found KMO only in microglia and neurons but not in astrocytes. Taken together, these data unexpectedly revealed that neurons contain a large proportion of functional $\mathrm{KMO}$ in the adult mouse brain under both physiological and pathological conditions.
\end{abstract}

Keywords: astrocyte; Huntington's disease; kynurenine pathway; microglia; schizophrenia

\section{Introduction}

Kynurenine 3-monooxygenase (KMO) catalyzes the conversion of L-kynurenine to 3hydroxykynurenine (3-HK) in the kynurenine pathway (KP), the major route of tryptophan degradation in eukaryotic organisms. While 3-HK is mainly known for generating reactive oxygen species and thereby causing oxidative damage, it is also able to scavenge free radicals and therefore has remarkable antioxidant properties. Importantly, because of its pivotal position in the KP, KMO is not only critical for 3-HK formation but controls the synthesis of several other biologically active KP metabolites, including kynurenic acid (KYNA), xanthurenic acid, 3-hydroxyanthranilic acid, xanthurenic acid, quinolinic acid, 
picolinic acid and cinnabarinic acid [1]. An NADPH-dependent enzyme located in the outer mitochondrial membrane [2-4] and linked to mitochondrial function [5], KMO is widely expressed in peripheral tissues, macrophages and monocytes [6,7]. Notably, as a number of KP metabolites are increasingly perceived to have considerable significance in normal brain function (see [8], for review), impaired KMO activity may play a substantive role in the pathophysiology of several neurological and psychiatric diseases [9-12]. For both conceptual and translationally relevant reasons, it is therefore essential to have a clear understanding of the cellular localization of KMO in the brain in health and disease.

Based almost entirely on studies of various cell types or immortalized cell lines in vitro, the prevailing view is that $\mathrm{KMO}$ in the central nervous system is predominantly localized in microglial cells (Figure 1) [13-15], and that inflammatory conditions greatly stimulate enzyme activity in these cells [13,16-19]. However, the presence of KMO has also been described in neurons and astrocytes in the rat brain [20]. KMO readily converts kynurenine to 3-HK in cultured fetal human neurons [21,22], and both KMO expression and function have been reported to be up-regulated in neurons in a mouse model of neuropathic pain [23]. Unfortunately, since state-of-the-art experimental in vivo tools have not been applied in this context so far, the present dogma that the major proportion of KMO in the mammalian brain is localized in microglial cells should therefore be considered with appropriate caution.

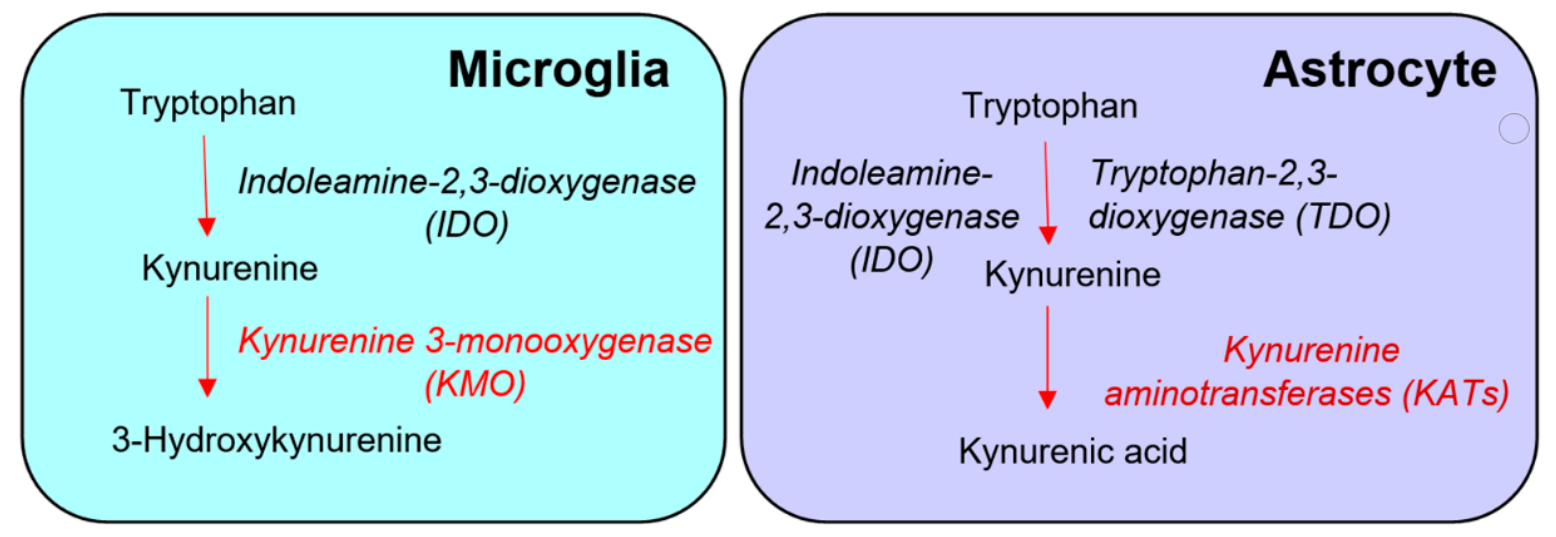

Figure 1. Conventional "glio-centric" view of the distinct de novo formation of 3-hydroxykynurenine and kynurenic acid in microglia and astrocytes, respectively.

The present study was designed to examine the cellular localization of KMO in the mouse brain using two strategies. In a first approach, animals were treated for 3-4 weeks with the CSF1R inhibitor PLX5622. This procedure selectively eliminates more than $95 \%$ of microglial cells under both physiological and pathological conditions, though microglial re-population occurs rapidly once the treatment is discontinued [24-26]. Experiments were performed both in normal animals and in R6/2 mice, an established model of Huntington's disease (HD; [27]), which shows microglial activation [28] and elevated KMO activity [29] in several brain areas. Because fluctuations in KMO activity play a critical role in the formation and function of the prominent neuromodulator KYNA, which is mainly synthesized in astrocytes (Figure 1) [30-35], we determined both enzyme activity and the brain tissue levels of 3-HK and KYNA in these studies.

In a complementary approach, we examined both Kmo expression and $\mathrm{KMO}$ activity in microglial cells, neurons and astrocytes that were acutely purified from healthy mouse forebrain using magnetic beads [36] and a neuron isolation kit [37].

\section{Materials and Methods}

\subsection{Experimental Tools}

3-HK, L-kynurenine ("kynurenine"), KYNA, NADPH, glucose-6-phosphate and glucose 6-phosphate dehydrogenase (GAPDH) were obtained from Sigma Aldrich (St. Louis, MO, USA). The KMO inhibitor Ro 61-8048 was a generous gift from Dr. Wolfgang Fröstl 
(Novartis, Basel, Switzerland). PLX5622 was provided by Plexxikon Inc. (South San Francisco, CA, USA) and formulated in standard AIN-76A chow (Research Diets, New Brunswick, NJ, USA).

MojoSort ${ }^{\mathrm{TM}}$ Buffer, anti-PE Nanobeads and anti-APC nanobeads, as well as PEconjugated anti-mouse/human CD11b, APC-conjugated anti-mouse CD24 and Alexa Fluor 488 anti-mouse/rat MAP2 antibodies, were purchased from BioLegend (San Diego, CA, USA). Permeabilizing Solution 2 was obtained from BD Biosciences (San Diego, CA, USA). Rabbit anti-mouse kmO antibodies were provided by Avivas (San Diego, CA, USA). Mouse anti-mouse/rat GFAP-Cy3, mouse anti-mouse/rat/human NeuN and donkey anti-mouse IgG-Alexa 488 antibodies were purchased from AbCam (Boston, MA, USA), and mouse anti-mouse/rat/human Iba1 antibodies were from SantaCruz Biotechnology (Dallas, TX,

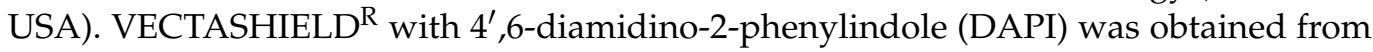
Vector Laboratories (Burlingame, CA, USA). Neuron isolation kits, PE-conjugated antimouse/rat GLAST antibodies and red blood cell lysis solution were provided by Miltenyi Biotech (San Diego, CA, USA), and anti-rabbit-Alexa Fluor 488 as well as anti-rabbit-Alexa Fluor 549 antibodies were purchased from Invitrogen (Carlsbad, CA, USA). All other chemicals were of the highest commercially available purity.

\subsection{Animals}

University of Maryland: Two-month-old male C57BL/6J mice, obtained from Jackson Laboratory (Bar Harbor, ME), were housed in a temperature-controlled, AAALACapproved animal facility on a 12/12 h-light/dark cycle with unlimited access to food and water. The experimental protocol was approved by the Institutional Animal Care and Use Committee (IACUC) of the University of Maryland School of Medicine.

University of Wyoming: R6/2 HD mice (originally from Jackson Laboratory) were maintained by crossing R6/2 males with B6/CBA F1 females. Mice were given ad libitum access to food and water on a 12/12 h-light/dark cycle. Progeny were genotyped at 3 weeks of age using DNA obtained from tail tips, weaned at 3.5 weeks, and then assigned to cages based on HD gene status. The experimental protocol was approved by the IACUC of the University of Wyoming.

S.S.A. Ciudad de México: For the isolation of brain cells, 2-month-old mice (C57BL/6J) were obtained from the vivarium of the National Institute of Neurology and Neurosurgery (México City, México). The animals were housed in a temperature-controlled facility on a 12/12h-light/dark cycle with unlimited access to food and water. All procedures were carried out according to the National Institutes of Health Guide for the Care and Use of Laboratory Animals, and the local guidelines on the ethical use of animals from the Health Ministry of México.

\subsection{PLX5622 Treatment In Vivo}

University of Maryland: Animals were fed PLX5622 (1200 ppm in chow) or standard AIN-76A rodent chow ad libitum for 21 days. Either on the next day or after receiving normal chow for an additional 21 days, mice were euthanized in a $\mathrm{CO}_{2}$ chamber. The brains were then quickly removed, frozen on dry ice and stored at $-80^{\circ} \mathrm{C}$ until analysis.

University of Wyoming: Animals were fed PLX5622 (1200 ppm in chow) or standard AIN-76A rodent chow ad libitum for 28 days starting at 7.5 weeks of age. On the last day of treatment, mice were deeply anesthetized using a B-euthanasia solution and perfused with cold $0.9 \%(w / v)$ saline for 2 min via the left ventricle. The brains were then quickly removed, frozen on dry ice and stored at $-80{ }^{\circ} \mathrm{C}$ until analysis.

\subsection{Analyses of Brain Tissue Following In Vivo Treatment}

\subsubsection{Expression of Microglial Markers and Kmo}

Total mRNA was extracted from frozen brains using an RNeasy Mini Kit (Qiagen, Germantown, MD, USA), and cDNA was synthesized using iScript cDNA Synthesis kit (Bio-Rad, Hercules, CA, USA). RT-PCR for AIF1, CSF1R, CX3CR1, Siglech, Tmem119, Kmo 
and $G A P D H)$ was performed using ABI TaqMan Expression Assays (Thermo-Fisher, San Francisco, CA, USA) (assay IDs: Mm00479862_g1, Mm01266652_m1, Mm00438354_m1, Mm00618627_m1, Mm01321343_m1 and Mm99999915_g1, respectively). Ct values were normalized to GAPDH and expressed as a percent of control.

\subsubsection{KMO Activity}

Brain samples were weighed while frozen, homogenized $(1: 5, w / v)$ by sonication in ultrapure water, and further diluted 1:5 (v/v) in Tris- $\mathrm{HCl}$ buffer, $\mathrm{pH} 8.1$, containing $10 \mathrm{mM}$ $\mathrm{KCl}$ and $1 \mathrm{mM}$ EDTA. The reaction mixture contained $80 \mu \mathrm{L}$ of this solution, $1 \mathrm{mM} \mathrm{NADPH}$, $3 \mathrm{mM}$ glucose 6-phosphate, GAPDH (1 U) and $100 \mu \mathrm{M}$ kynurenine in a total volume of $0.2 \mathrm{~mL}$. Samples were incubated at $37^{\circ} \mathrm{C}$ for $40 \mathrm{~min}$ in a shaking water bath. Blanks were obtained by adding the KMO inhibitor Ro 61-8048 (final concentration: $100 \mu \mathrm{M}$ ) to the incubation solution. The reaction was terminated by the addition of $50 \mu \mathrm{L}$ of $6 \%$ perchloric acid. The samples were centrifuged $(16,000 \times g, 15 \mathrm{~min})$, and the resulting supernatant was diluted as needed. Twenty $\mu \mathrm{L}$ of the solution were then subjected to HPLC analysis of 3-HK, as described below.

\subsubsection{3-Hydroxykynurenine (3-HK)}

Twenty-five $\mu \mathrm{L}$ of $6 \%$ perchloric acid were added to $100 \mu \mathrm{L}$ of the original brain homogenate. After thorough mixing, the precipitated proteins were removed by centrifugation $(16,000 \times g, 15 \mathrm{~min})$. Twenty $\mu \mathrm{L}$ of the resulting supernatant were applied to a $3 \mu \mathrm{m}$ HR80 column $(80 \times 4.6 \mathrm{~mm}$, Thermo-Fisher Scientific, Waltham, MA, USA), using a mobile phase consisting of $1.5 \%$ acetonitrile, $0.9 \%$ triethylamine, $0.59 \%$ phosphoric acid, $0.27 \mathrm{mM}$ sodium EDTA and $8.9 \mathrm{mM}$ heptane sulphonic acid and a flow rate of $0.5 \mathrm{~mL} / \mathrm{min}$. In the eluate, 3-HK was detected electrochemically (Eicom HTEC-500; San Diego, CA, USA) at an oxidation potential of $+0.5 \mathrm{~V}$. The retention time of $3-\mathrm{HK}$ was $\sim 11 \mathrm{~min}$.

\subsubsection{Kynurenic Acid (KYNA)}

Twenty $\mu \mathrm{L}$ of the solution used for the analysis of 3-HK (see above) were applied to a 3- $\mu \mathrm{m}$ ReproSil C18 column (100 mm × 4 mm; Dr. Maisch GmbH, Ammerbuch, Germany) to quantify KYNA. KYNA was isocratically eluted at a flow rate of $0.5 \mathrm{~mL} / \mathrm{min}$, using a mobile phase containing $50 \mathrm{mM}$ sodium acetate and $3 \%$ acetonitrile $(\mathrm{pH}$ adjusted to 6.2 with glacial acetic acid). After post-column derivatization with $500 \mathrm{mM}$ zinc acetate, delivered at a flow rate of $0.1 \mathrm{~mL} / \mathrm{min}$, KYNA was determined in the eluate by fluorometric detection (excitation: 344 nm, emission: 398 nm; Perkin-Elmer series 200; Waltham, MA, USA). The retention time of KYNA was $\sim 18 \mathrm{~min}$.

\subsection{Isolation of Brain Cells}

Mice were decapitated, and their brains were rapidly collected and washed with ice-cold phosphate-buffered saline (PBS). Forebrains were then immediately chopped, and $2 \mathrm{~mL}$ of accutase were added to achieve cell disaggregation. Next, $1 \mathrm{~mL}$ of fresh Dulbecco's Modified Eagle Medium (DMEM), supplemented with 10\% of fetal bovine serum (FBS), was added, and the cell suspension was filtered through pre-separation filters (70 $\mu \mathrm{m}$; Miltenyi Biotec). After adjusting the volume to $10 \mathrm{~mL}$ with DMEM containing 10\% of FBS, the samples were centrifuged $(300 \times g, 10 \mathrm{~min})$, and the supernatant was discarded. Subsequently, myelin sheaths and cell debris were removed using a debris removal solution (Miltenyi Biotec), and samples were centrifuged at $3000 \times g(10 \mathrm{~min})$. The supernatant was discarded, and the pellets were washed with $15 \mathrm{~mL}$ of PBS and re-centrifuged $(1000 \times g$, $10 \mathrm{~min})$. Following removal of the supernatant, addition of a red blood cell lysis solution $(900 \mu \mathrm{L})$, and incubation for $10 \mathrm{~min}$ at $4^{\circ} \mathrm{C}, 10 \mathrm{~mL}$ of PBS were added, and samples were centrifuged $(300 \times g ; 10 \mathrm{~min})$. The resulting pellet was re-suspended in $200 \mu \mathrm{L}$ of PBS and separated into two different pools to add PE-conjugated GLAST, PE-conjugated CD11b or APC-conjugated D24 antibodies (all in a final concentration of $1 \mu \mathrm{g} / \mathrm{mL}$ ). After incubation in darkness at room temperature (30 min), cells were washed with $4 \mathrm{~mL}$ MojoSort buffer 
and centrifuged at $300 \times g(5 \mathrm{~min})$. Cells were then re-suspended in $100 \mu \mathrm{L}$ of MojoSort buffer with $10 \mu \mathrm{L}$ of anti-PE nanobeads or anti-APC nanobeads, incubated for 15 min on ice, washed with $4 \mathrm{~mL}$ of MojoSort buffer, and again centrifuged at $300 \times g$ (5 min). For separation, $2.5 \mathrm{~mL}$ of MojoSort buffer were added, and each tube was placed for $5 \mathrm{~min}$ in a MojoSort magnet. Unattached cells were discarded. The remaining cells were suspended in $2.5 \mathrm{~mL}$ of MojoSort buffer and again placed in the magnet. This step was repeated twice for each tube. After cell separation, GLAST+, CD11b+ and CD24+ cells were collected to examine purity and yield, Kmo mRNA expression, and KMO activity.

Using a neuron isolation kit, the cell suspension obtained after disaggregation and debris removal (see above) was mixed with $20 \mu \mathrm{L}$ of a non-neural cell biotin-antibody cocktail for $10 \mathrm{~min}$ in darkness at $4^{\circ} \mathrm{C}$. Cells were then washed with $1 \mathrm{~mL}$ of D-PBS/BSA buffer, centrifuged $(300 \times g, 5 \mathrm{~min})$ and re-suspended in $80 \mu \mathrm{L}$ of D-PBS/BSA. Twenty $\mu \mathrm{L}$ of a solution containing anti-biotin microbeads were then added, and the mixture was incubated in darkness at $4{ }^{\circ} \mathrm{C}(10 \mathrm{~min})$. Magnetic cell separation was performed with LS columns in a MidiMACS cell separator (Proteintech, San Diego, CA, USA). After isolation, neurons were treated with permeabilizing "Solution 2" as per the manufacturer's instructions and incubated with Alexa Fluor 488 MAP2 primary antibody (1:100) for cell purity determination and measurement of KMO activity.

Following cell separation, the purity of astrocytes, microglia and neurons was determined using fluorescence-activated cell sorting (FACS) and Calibur flow cytometer software (Becton-Dickinson, San Jose, CA, USA), acquiring 10,000 total events. CellQuestPro and Flowjo software were used for analysis.

\subsection{Analyses of Isolated Brain Cells}

\subsubsection{Kmo Expression}

Separated astrocytes, microglial cells and neurons were treated with Trizol (ThermoFisher) for RNA isolation. cDNA was obtained using the 1st Strand cDNA Synthesis Kit. RT-PCR for KMO and GAPDH was performed using KMO Mouse qPCR primer pair NM_133809, MP207238, GAPDH mouse qPCR primer pair MP 008084, and SensiFAST SYBR Master Mix Lo-Rox Kit. All tools used were obtained from OriGene (Rockville, MD, USA). CT values were normalized to GAPDH.

\subsubsection{FACS Analysis}

Separated astrocytes, microglia and neurons, surface-stained with anti-GLAST-PE, CD11b-PE and CD24-APC antibodies, respectively (see above), were processed for intracellular staining. Using a permeabilizing solution, cells were incubated for 30 min with an anti $\mathrm{kmO}$ antibody (diluted 1:100) and were then washed once with PBS and incubated for 30 min with Alexa Fluor 488 (diluted 1:200) as a secondary antibody. FACS analysis was performed using a FACS Calibur flow cytometer (Becton-Dickinson), acquiring 10,000 total events. CellQuestPro and Flowjo software were used for analysis. Fluorescence minus One (FMO) control as well as unstained samples were used to set compensations and gating strategy, and data were analyzed using FlowJo v.10 software.

\subsubsection{Immunofluorescence}

Purified astrocytes, microglial cells and neurons were fixed with 100\% methanol and mounted on slides. Antibodies against CD11b, GFAP-Cy3 and NeuN (all diluted 1:200), were then used to verify respective cellular identities. As a secondary antibody for NeuN, Alexa 488 was used. Additionally, cells were incubated with anti kmO antibodies (Alexa 488 for microglia and astrocytes, and Alexa 549 for neurons). After incubation (30 min, room temperature) and 3 washes with PBS, each covering the slides for $5 \mathrm{~min}$, slides were mounted using Vectashield with DAPI to counterstain the nucleus and were then sealed with nail polish. Images were taken using a Motic AE31Elite fluorescence microscope equipped with a CMOS camera (Photonfocus, Rockville, MD, USA). 


\subsubsection{Quantitation of Cells}

To determine the percentage of each cell type in the mouse forebrain, debris and red blood cells were removed from the original brain tissue homogenate, and cells were separated (see above). Respective antibodies (GFAP and GLAST for astrocytes, CD11b and Iba1 for microglia, and MAP2 for neurons) were then added to the suspension, and cells were quantitated by FACS as described above.

\subsubsection{KMO Activity}

To determine KMO activity in separated astrocytes, microglia and neurons, $150 \mu \mathrm{L}$ of isolated cell preparations (at least $1 \times 10^{5}$ cells for each type) were diluted $(1: 2, \mathrm{v} / \mathrm{v})$ in Tris- $\mathrm{HCl}$ buffer, $\mathrm{pH} \mathrm{8.1,} \mathrm{containing} 10 \mathrm{mM} \mathrm{KCl}$ and $1 \mathrm{mM}$ EDTA. Using the same reaction mixture described above, $80 \mu \mathrm{L}$ of the samples were incubated at $37^{\circ} \mathrm{C}$ for $2 \mathrm{~h}$ in a shaking water bath. Blanks were obtained using boiled samples (10 min). The reaction was terminated by the addition of $25 \mu \mathrm{L}$ of $6 \%$ perchloric acid. After centrifugation $(16,000 \times g$, $10 \mathrm{~min})$, the resulting supernatants were diluted as needed, and $100 \mu \mathrm{L}$ were applied to a $3 \mu \mathrm{m}$ HPLC column (Adsorbosphere C18, $100 \mathrm{~mm} \times 4.6 \mathrm{~mm}$, Fisher Scientific, Hampton, $\mathrm{NH}$ ), using a mobile phase consisting of $1.5 \%$ acetonitrile, $0.9 \%$ triethylamine, $0.59 \%$ phosphoric acid, $0.27 \mathrm{mM}$ sodium EDTA and $8.9 \mathrm{mM}$ heptane sulphonic acid and a flow rate of $0.6 \mathrm{~mL} / \mathrm{min}$. 3-HK was detected electrochemically using a LC-4C detector (BAS, West Lafayette, IN; oxidation potential: $+0.5 \mathrm{~V}$ at a range $1.0 \mathrm{nA}$ and a filter of $0.10 \mathrm{~Hz})$. The retention time of 3-HK was $\sim 11 \mathrm{~min}$.

\subsection{Protein Determination}

In all experiments, protein content was determined by adaptations of the method of Lowry et al. (1951), using bovine serum albumin as a standard [38].

\subsection{Statistical Analyses}

All data are expressed as the mean \pm SEM. Statistical analysis was performed using the Kruskal-Wallis test with Dunn's test for multiple pairwise comparisons. When comparing only two groups, a Mann-Whitney test was performed. Values of $p<0.05$ were considered significant.

\section{Results}

\subsection{Effect of PLX5622 Treatment in Healthy Mice}

Real time PCR analysis of the microglial marker genes Aif1 (-89\%), Csf1r (-97\%), Cx3cr1 (-97\%), Siglech (-97\%) and Tmem119 (-90\%) confirmed that daily administration of PLX5622 for 21 days caused the massive depletion of microglial cells in the forebrain of normal mice. However, the expression of these microglial markers was fully recovered 22 days after discontinuation of the treatment (Figure 2). 


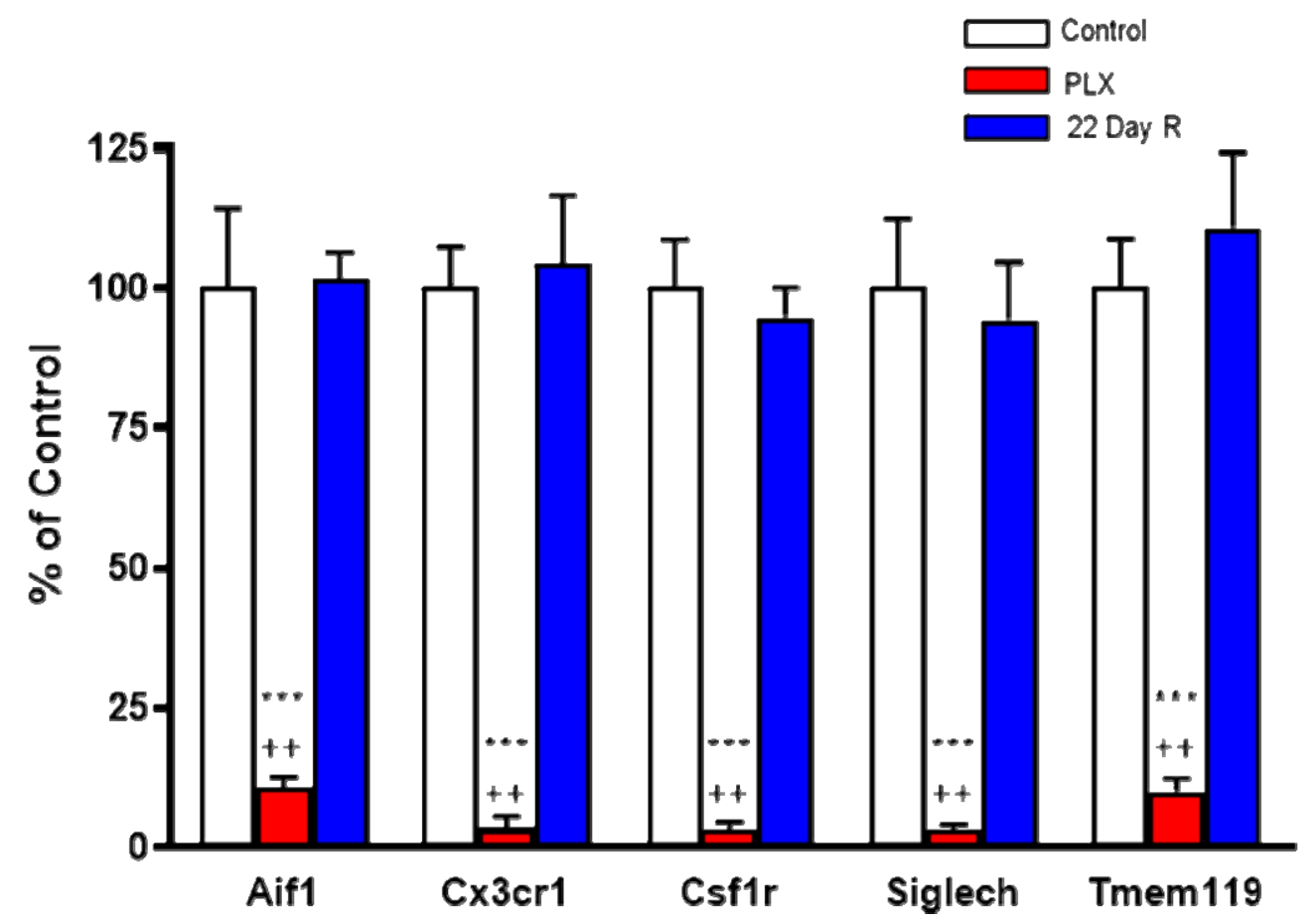

Figure 2. Effect of PLX5622 (PLX) treatment on microglial marker genes. Wild-type controls and PLX5622: $n=6$ each; 22-day recovery (R): $n=3$. Data (mean \pm SEM) are expressed as a percentage of control values. See text for experimental details. ${ }^{* * *} p<0.01$ vs. control, ${ }^{++} p<0.05$ vs. 22 -day recovery (Kruskal-Wallis test with Dunn's test for multiple pairwise comparisons).

In the same animals, neither Kmo expression nor KMO activity were significantly changed in the forebrain immediately after the treatment with PLX5622 or after a 22-day recovery period (Figure 3A,B). Forebrain 3-HK and KYNA levels, too, were not significantly affected by PLX5622 immediately after the treatment was terminated or 22 days later (Figure 3C,D).

\subsection{Effect of PLX5622 Treatment in R6/2 Mice}

We next examined the effect of prolonged PLX5622 treatment of R6/2 mice, a wellestablished animal model of HD which shows pronounced microglial activation [28]. As reported earlier [29] and confirmed here, KMO activity was significantly elevated in the brain in R6/2 mice compared to wild-type controls. However, PLX5622 had no effect on KMO activity, 3-HK and KYNA levels in the forebrain of either wild-type or R6/2 mice (all $p>0.05$; Figure $4 \mathrm{~A}-\mathrm{C}$ ). In agreement with the results obtained in normal mice (cf. Figure 3), PLX5622 also failed to influence KMO activity and the tissue concentrations of 3-HK and KYNA in the forebrain of the respective control animals (Figure 4A-C). 
A

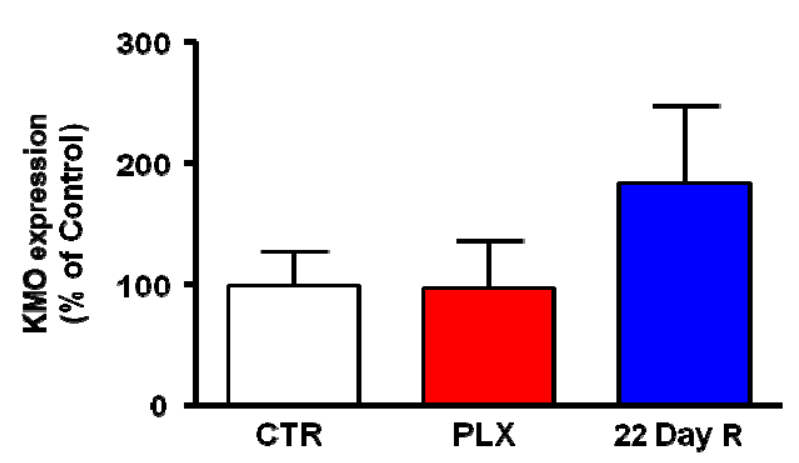

C

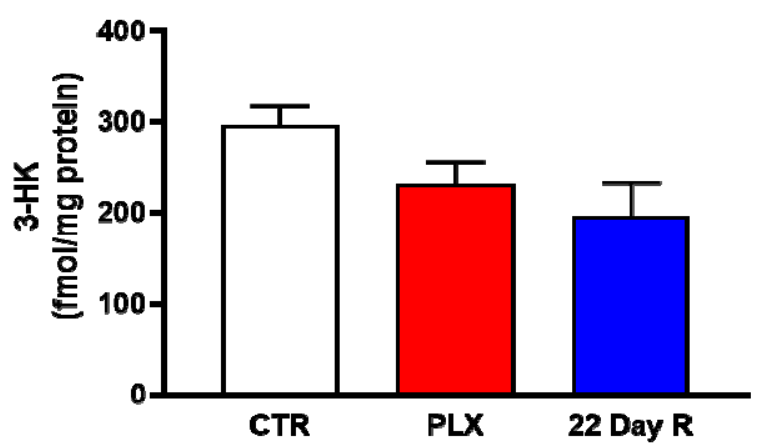

B

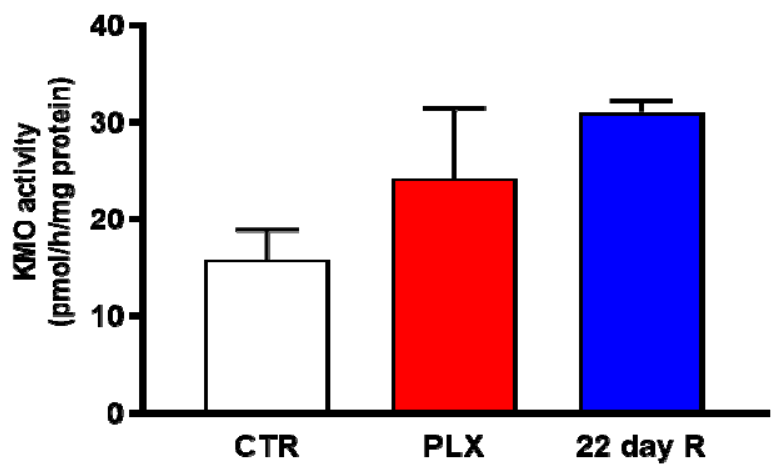

D

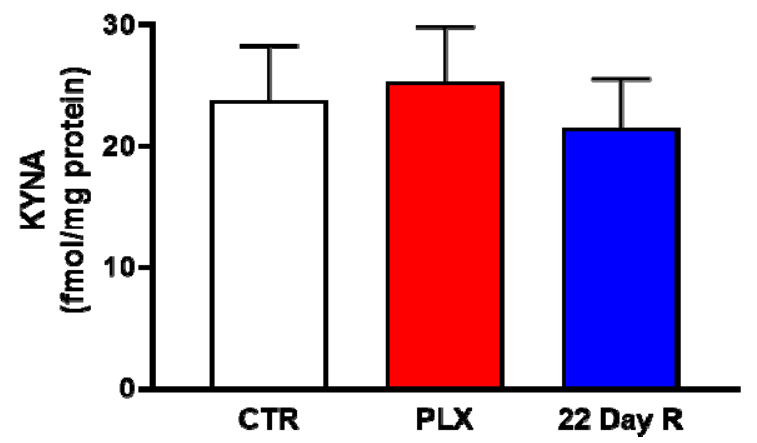

Figure 3. Effect of PLX5622 (PLX) on Kmo expression (A), KMO activity (B), 3-HK levels (C) and KYNA levels (D) in the forebrain of the same wild-type mice used to examine microglial marker genes (same $n$ /group as in Figure 2). Data are the mean \pm SEM. See text for experimental details. Kruskal-Wallis test, with Dunn's test for multiple pairwise comparisons, revealed no significant group differences $(p>0.05)$.
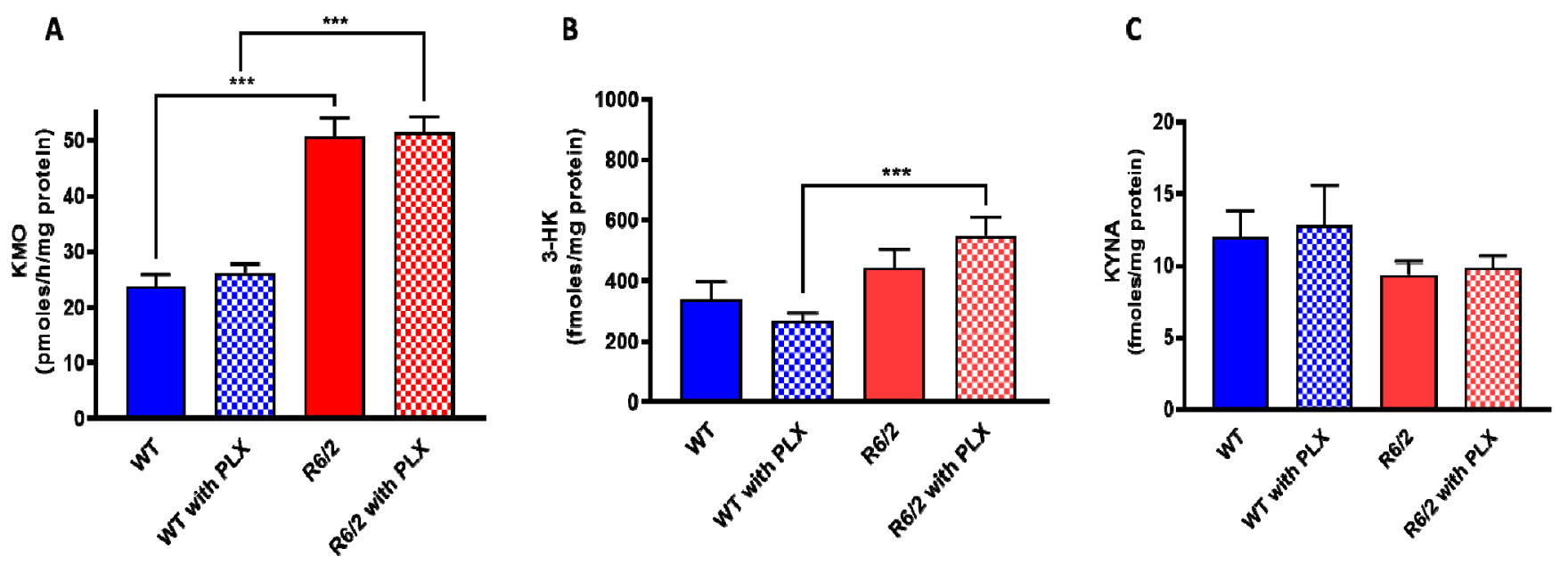

Figure 4. Effect of PLX5622 (PLX) on KMO activity (A), 3-HK (B) and KYNA (C) levels in the forebrain of wild-type (WT) and R6/2 mice. Data are the mean \pm SEM ( $n=10$ per group). See text for experimental details. ${ }^{* *} p<0.001$ (Kruskal-Wallis test with Dunn's test for multiple pairwise comparisons). 


\subsection{Kmo Expression and KMO Protein in Freshly Isolated Brain Cells}

In light of the unexpected failure to affect Kmo expression and activity, as well as 3-HK and KYNA levels, by experimentally depleting the vast majority of microglial cells in the brain in vivo, we decided to magnetically separate astrocytes, microglia, and neurons from whole mouse brain to examine the presence of KMO in each cell type. The purity of the freshly isolated cells was evaluated with specific surface markers for astrocytes (GLAST-PE), microglia (CD11b-PE) and neurons (CD24-APC). As illustrated in Figure 5A-C, the purity obtained using this procedure was $94.5 \pm 1.0 \%$ for astrocytes, $92.5 \pm 0.8 \%$ for microglia, and $95.7 \pm 1.7 \%$ for neurons. Notably, microglia and neurons showed substantial Kmo expression, whereas no signal was detected in astrocytes (Figure 5D).

A

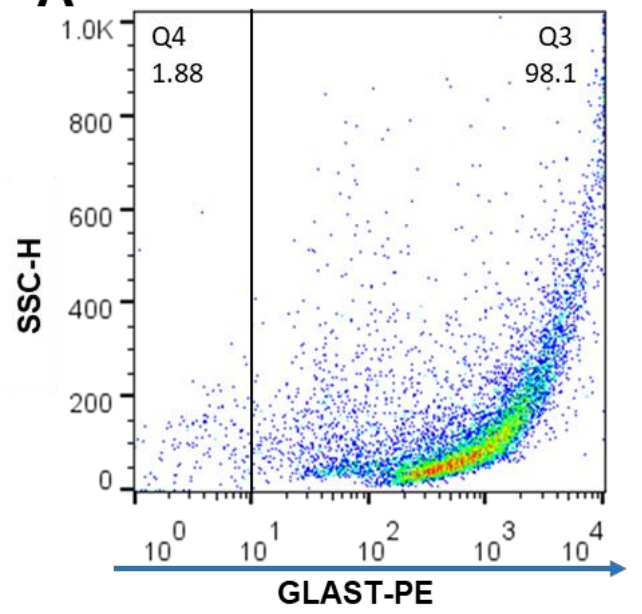

C

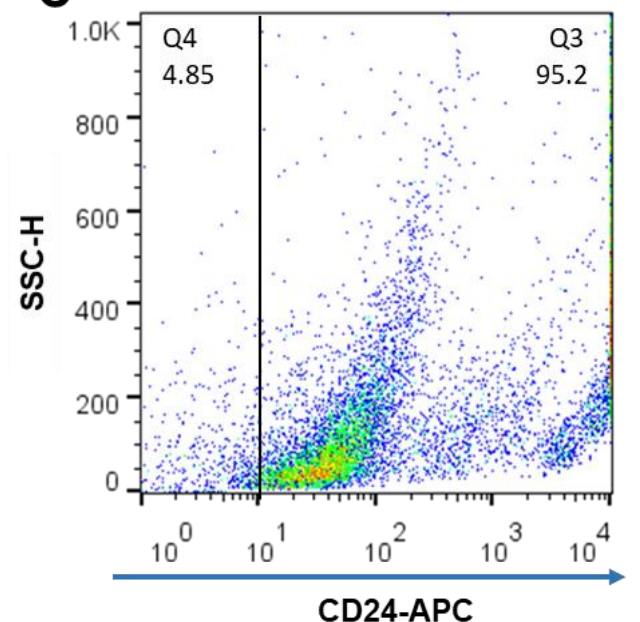

B

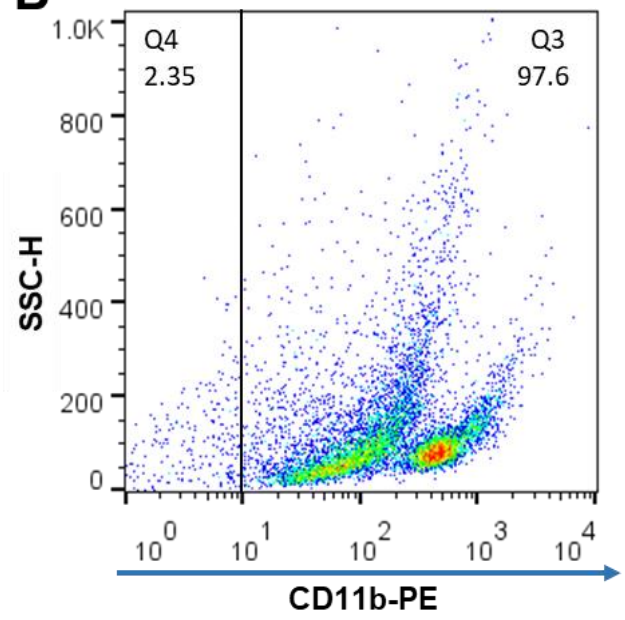

D

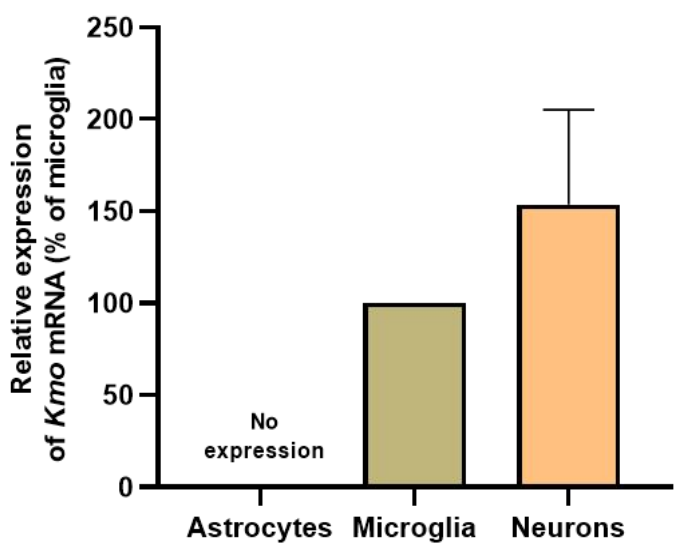

Figure 5. (A-C) Representative dot plots of side scatter height (SSC-H) vs. its corresponding marker, illustrating the purity of brain cells that were isolated from 6 separate mouse brains. After magnetic cell separation, the purity of astrocytes (GLAST-PE+), microglia (CD11b-PE+) and neurons (CD24APC+) was evaluated by flow cytometry; (D) Kmo mRNA, determined by RT-qPCR. Data are the mean \pm SEM. See text for experimental details. 
Next, KMO protein in these cells was examined by flow cytometry and immunofluorescence. In line with the Kmo mRNA expression data described above, double-staining revealed that less than $4 \%$ of GLAST+ cells, i.e., astrocytes, were KMO-positive (Figure 6A) whereas KMO was present in $95 \%$ of CD11b+ (Figure $6 \mathrm{~B}$ ) and $90 \%$ of CD24+ (Figure 6C) cells. Representative microscopic images of the cells, using anti-CD11b-PE, anti-NeuNAlexa 488 and anti-GFAP-Cy3 antibodies to selectively stain microglia, neurons and astrocytes, respectively, are shown in Figure 7.

A

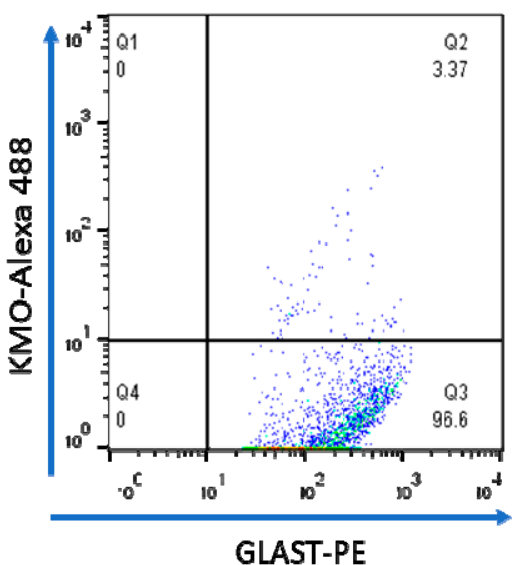

B

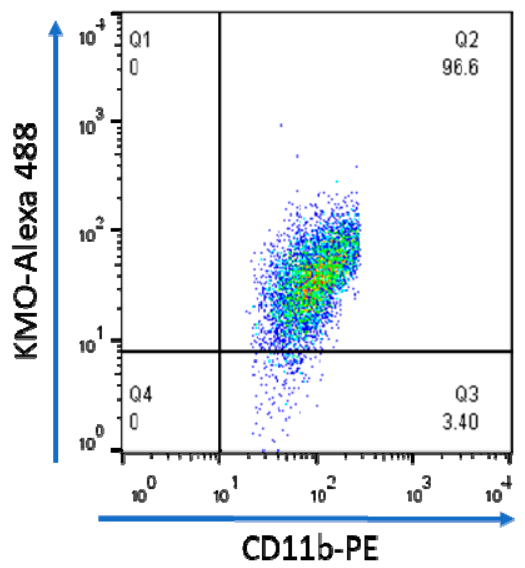

C

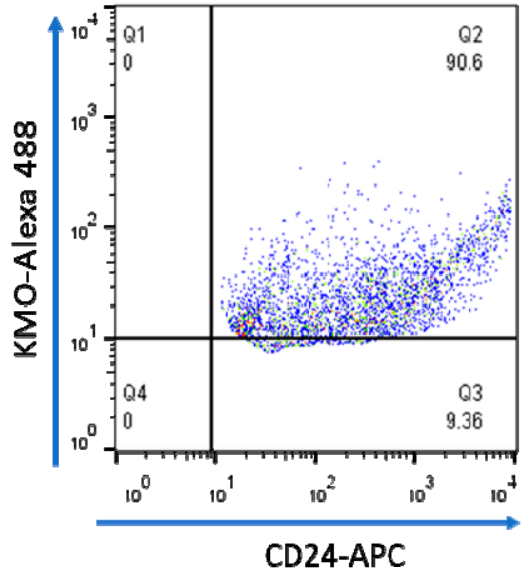

Figure 6. Dot plots illustrating intracellular staining of KMO protein in purified brain cells, assessed by FACS. The percentage of KMO+ cells in (A) astrocytes (GLAST-PE), (B) microglia (CD11b-PE) and (C) neurons (CD24-APC) is shown in Q2. See text for experimental details.

\subsection{KMO Activity in Freshly Isolated Brain Cells}

We next assessed the relative proportion of astrocytes, microglial cells and neurons in whole brain homogenate in order to determine their relative contribution to KMO activity in the normal mouse brain. Using specific markers for each cell type (GFAP and GLAST for astrocytes, CD11b and Iba1 for microglia, and MAP2 for neurons), the percentage of astrocytes was $\sim 30 \%$ (GFAP: $34 \pm 3 \%$, GLAST: $27 \pm 1 \%$ ), the percentage of microglial cells was $\sim 15 \%$ (CD11b: $12 \pm 2 \%$, Iba1: $15 \pm 1 \%$ ), and the percentage of neurons was $29 \pm 5 \%$ (Figure 8A). KMO activity was detectable in microglia and neurons but not in astrocytes. Notably, specific enzyme activity was significantly higher in neurons than in microglial cells (Figure 8B). 


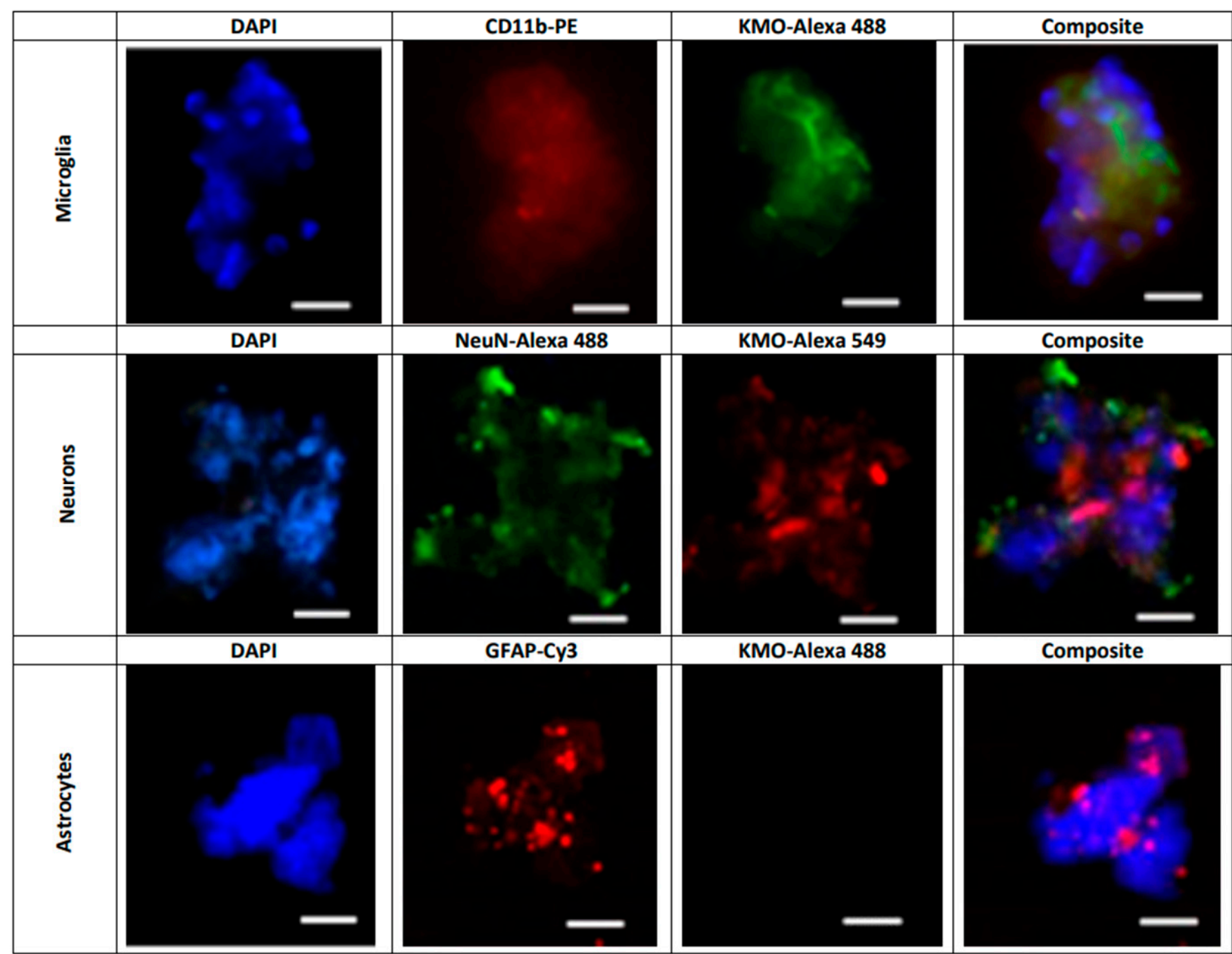

Figure 7. Representative images illustrating the presence of KMO protein in freshly isolated microglial cells (CD11b-PE: red), neurons (NeuN-Alexa 488: green) and astrocytes (GFAP-Cy3; red). Nuclei were stained with DAPI (blue). KMO was identified using anti-rabbit Alexa 488 in microglia and astrocytes, and anti-rabbit Alexa 549 in neurons, as secondary antibodies. See text for experimental details. Images were acquired at $40 \times$ magnification. Scale bars: $20 \mu \mathrm{m}$. 
A

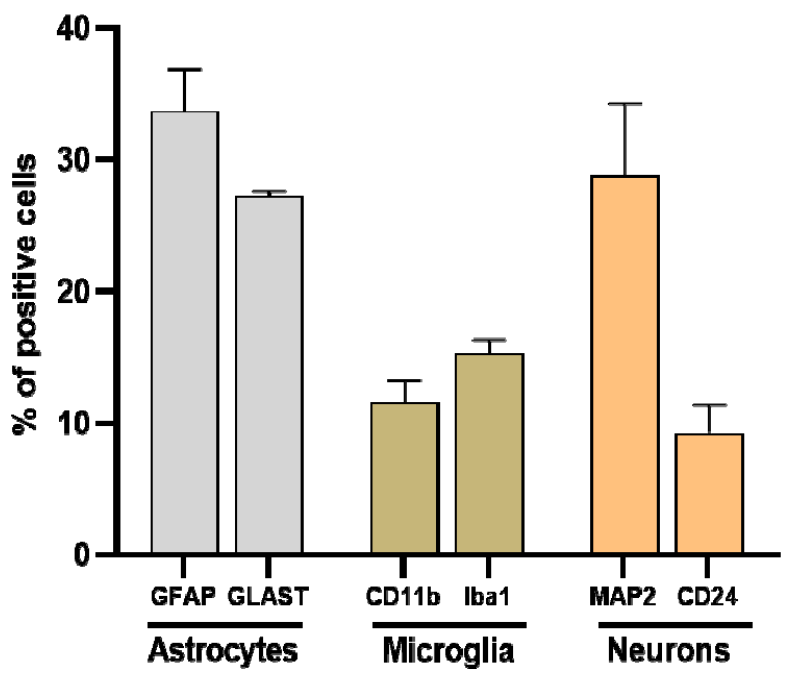

B

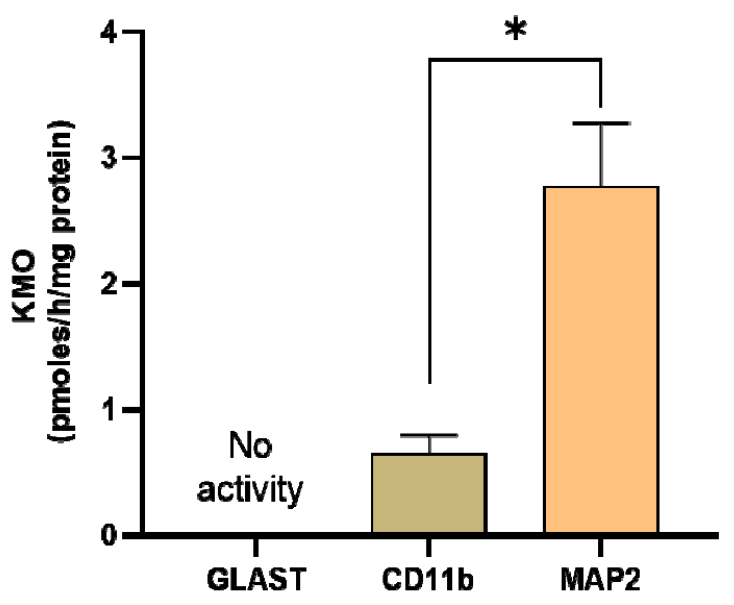

Figure 8. (A) Proportion of astrocytes, microglia, and neurons, assessed in whole mouse brain homogenate $(n=4-6)$. Cell suspensions were incubated with markers for astrocytes (GFAP and GLAST), microglia (CD11b and Iba1) and neurons (MAP2), respectively. See text for experimental details; (B) KMO activity in isolated cells ( $>90 \%$ purity). Data are the mean \pm SEM. ${ }^{*} p<0.01$ (Mann-Whitney test).

\section{Discussion}

Using complementary experimental approaches, the present study was designed to examine the cellular localization of the KP enzyme KMO in the mouse brain. Using wild-type and HD model mice, we first determined both the expression and the activity of KMO and measured the levels of the KP metabolites 3-HK and KYNA, in brain tissue after selectively depleting microglia in vivo with the brain-penetrant CSF1R antagonist PLX5622 [24]. Unexpectedly, our results did not support the widely accepted view that a large majority of brain $\mathrm{KMO}$ is localized in microglial cells, and that these cells account for the increase in KMO activity seen under various pathological conditions. We then assessed the presence of KMO biochemically and microscopically ex vivo in microglial cells, astrocytes and neurons after they were acutely isolated from normal mice. While we confirmed previous studies in rats, gerbils and humans, which had shown that only very little-if any-KMO is contained in astrocytes $[20,39,40]$, these experiments indicated that neurons may play a heretofore overlooked, substantive role in the regulation of KP function in brain physiology and pathology.

Due to the rapidly growing awareness of the multi-faceted neurobiological effects of several KP metabolites, and the insight that even relatively minor fluctuations in the brain levels of these compounds have biologically relevant functional consequences (see [1], for a recent comprehensive review), the pivotal location of KMO in the KP has made this enzyme an increasingly attractive focus of neuroscience research $[9,10,12]$. Notably, attention is not limited to the enzyme's immediate product 3-HK, though the dual antioxidant and neurotoxic properties of this metabolite are intriguing and may be of considerable biological significance [41]. KMO also controls the fate of xanthurenic acid (XA), a transamination product of 3-HK [42] which is gaining attention in neurobiology because of its effect on glutamatergic neurotransmission $[43,44]$ and its ability to modulate extracellular dopamine levels [45].

Notably, as demonstrated consistently in studies in animals, experimentally induced reductions in KMO activity raise the levels of the neuromodulator KYNA in the brain and elsewhere [30,31,34]. This functional connection between KMO and KYNA affects brain physiology [46-49] and may also have significant pathophysiological relevance since both 
impaired KMO activity and abnormal KYNA levels are seen in several neurological and psychiatric disorders including HD [50], epilepsy [51], schizophrenia [52-54], and bipolar disorder $[35,55]$. For this reason, we measured the brain tissue levels of both 3-HK and KYNA in our in vivo studies.

The realization that brain KYNA levels can be increased by KMO inhibition soon suggested attractive, novel therapeutic options [56-58]. Thus, reduced KMO activity would not only enhance the neuroprotective and anticonvulsant effects of KYNA [59], but at the same time decrease the synergistic adverse properties of 3-HK and its downstream product quinolinic acid, i.e., metabolites in the "neurotoxic branch" of the KP [60]. KMO inhibition was also envisioned to counter the detrimental effects of repeated stress or excessive immune activation, which have been proposed to play key roles in depressive disorders by increasing 3-HK and quinolinic acid levels in the brain [61-66]. It was soon understood, however, that elevated brain levels of KYNA — in line with the "Janus face" of the metabolite [67]—also have negative consequences, causing cognitive impairments due to interference with the function of both $\alpha 7$ nicotinic acetylcholine and NMDA receptors [68-71].

In mechanistic terms, the functional connection between KMO and KYNA is directly related to the fact that $\mathrm{KMO}\left(\mathrm{K}_{\mathrm{m}}\right.$ for kynurenine: $\sim 20 \mu \mathrm{M}$; [72]) is much more easily saturated by its substrate than kynurenine aminotransferases (KATs), i.e., KYNA's biosynthetic enzymes ( $K_{m}$ values for kynurenine: $>1 \mathrm{mM}$; [73]). In spite of the fact that KAT II, the main KAT responsible for the neosynthesis of rapidly mobilizable KYNA in the brain, is localized in astrocytes [32], i.e., in cells that do not contain $\mathrm{KMO}$, rising concentrations of kynurenine therefore shift KP metabolism in vivo increasingly toward the production of KYNA [74]. This effect is commonly explained by the fact that kynurenine, which is the substrate of both KMO and KAT, is taken up separately by microglia [75] and astrocytes [76].

In view of this widely accepted "glio-centric" view of cerebral KP metabolism (cf. Figure 1), the failure of PLX5622 treatment to affect cerebral KMO activity, 3-HK and KYNA levels in healthy mice as well as in a mouse model of HD showing microglial activation, was unexpected and difficult to interpret. However, our data were in line with a recent report showing that PLX5622 treatment in mice does not prevent the sickness-inducing effects of acute inflammation, which are supposed to be causally related to microglial stimulation [77]. Without referring explicitly to KMO, the authors suggested plausibly that experimental depletion of microglial cells may have caused the stimulation of immuneactivated genes in astrocytes or, less likely, enhanced trafficking of immune cells into the brain. Thus, although no KMO activity was detected in astrocytes in the present study, as yet undetermined compensatory astrocytic mechanisms may have accounted for the normal levels of 3-HK and KYNA seen in the brain of PLX5622-treated animals. Separately or in addition, compensatory changes in peripheral KP metabolism may be triggered by microglial ablation. Mechanisms may involve, for example, nitric oxide donors which inhibit the key upstream KP enzyme indoleamine-2,3-dioxygenase in macrophages but not in microglia [78,79], and may therefore affect entry of circulating kynurenines into the brain.

Since functionally significant activation of neuronal rather than microglial KMO accounts for depression-like behavior in a mouse model of neuropathic pain [23], a compensatory up-regulation of $\mathrm{KMO}$ in neurons appeared to be a possible alternative explanation of our in vivo results. In fact, neurons actively accumulate kynurenine [80], and the presence of KMO and KATs has been documented in a variety of mammalian neurons under both physiological and pathological conditions [20-22,81-84]. Our present observation that a majority of $\mathrm{KMO}$ in freshly isolated mouse brain cells was found in neurons was still unexpected, however. Although the cell isolation procedure, which is known to alter the gene expression profile of microglial cells and ought to be re-examined using a single-cell RNA-seq approach [85], may have affected our data in quantitative terms, these results imply that neurons play a far greater role in cerebral KP function than assumed.

While substantive species differences exist and must be taken into account [6,84], our new data indicate that the established, mostly glio-centric views of the nature of 
KP metabolism in the mammalian brain are too simplistic and should be re-visited. Of note in this context, selective neuronal ablation [74] as well as interference with astrocyte function [86] have distinct effects on cerebral KP metabolism in vivo but these observations, like the present study using PLX5622 to transiently incapacitate microglial cells, failed to provide a clear picture regarding the role(s) of KP-related cellular cross-talk in the brain. New, detailed approaches are therefore needed to elucidate the anatomical, biochemical and physiological features of KP metabolism, including the respective roles of receptors of KYNA and several other neuroactive KP metabolites, in distinct brain cells. Considering the complexities of cerebral KP function [1] as well as the critical role of peripherally derived kynurenine [87], special attention ought to be paid to additional cell types such as oligodendrocytes [88] and perivascular cells [89], and to the evaluation of brain region-specific heterogeneities. In view of the functionally relevant intricacies of the Kmo gene $[35,53,90]$ and the recently described presence of functional KMO in astrocytomas [91], it seems especially relevant to assess the localization and function of the third kynurenine-degrading enzyme, kynureninase $\left(\mathrm{K}_{\mathrm{m}}\right.$ : $\sim 35 \mu \mathrm{M}$; [92]), in parallel with KMO and KATs in these experiments.

\section{Conclusions}

The present results suggest that a possible functional role of neurons in KMO-related events in the brain should be examined in detail. As cellular co-localization of KMO with other KP enzymes is likely to change both qualitatively and quantitatively under pathological conditions, deciphering the related functional implications, including effects on neurobiologically relevant redox processes, presents some of the most interesting and translationally relevant challenges. Importantly, future efforts should focus not only on events in the adult brain but consider that biologically significant differences in cerebral KMO function-and in brain KP metabolism in general-may exist in the pre- and early postnatal period and/or late in life (see [93] and [94] for reviews).

Eventually, these novel insights will have to be integrated into the larger role of the KP in physiology and pathology, with special attention not only to the individual, and remarkably complex, redox properties of kynurenine [95,96], 3-HK $([97,98]$ and KYNA [99,100], but also to the equally intriguing pro- and antioxidant properties of the downstream KP metabolites 3-hydroxyanthranilic acid, xanthurenic acid, quinolinic acid, picolinic acid and cinnabarinic acid (cf. Introduction). Inflammatory processes (including immunosuppression and immunotolerance [101-104], as well as investigations related to cellular energy status [105,106], neurodegenerative and neuroprotective processes [42,107,108], will deserve special emphasis in this respect. In view of the increasing realization that the KP has "a finger in every pie" [109], all these studies can be expected to have a significant and translationally relevant impact in the field.

Author Contributions: Conceptualization: K.V.S., V.P.d.l.C., B.P., F.G., J.H.F. and R.S.; Methodology and data analysis: K.V.S., V.P.d.I.C., B.P., P.L.S., G.I.V.C., D.R.O., D.W.D. and J.H.F.; Draft preparation: K.V.S., V.P.d.I.C. and R.S.; Editing: K.V.S., V.P.d.1.C., B.P., F.G., D.W.D., P.L.S., B.L.W., J.H.F. and R.S. All authors have read and agreed to the published version of the manuscript.

Funding: This work was supported by NIH grants P50 MH103222 (Conte Center for Translational Research) and R01 NS079459, and CONACyT grant 317366.

Institutional Review Board Statement: At all three locations, studies were conducted according to the guidelines of the Declaration of Helsinki, and approved by the respective Institutional Review Boards [Protocol numbers: University of Maryland: 0414012; University of Wyoming: 20150929JG00198; S.S.A. Ciudad de México: protocol 111/19].

Informed Consent Statement: Not applicable.

Data Availability Statement: The datasets used in the current study are available from the corresponding author on reasonable request. 
Acknowledgments: The excellent technical assistance of Marian Thomas and Aleli Salazar is gratefully acknowledged.

Conflicts of Interest: The authors declare no conflict of interest.

\section{References}

1. Mithaiwala, M.N.; Santana-Coelho, D.; Porter, G.A.; O'Connor, J.C. Neuroinflammation and the kynurenine pathway in CNS disease: Molecular mechanisms and therapeutic implications. Cells 2021, 10, 1548. [CrossRef] [PubMed]

2. Okamoto, H.; Hayaishi, O. Flavin adenine dinucleotide requirement for kynurenine hydroxylase of rat liver mitochondria. Biochem. Biophys. Res. Commun. 1967, 29, 394-399. [CrossRef]

3. Hirai, K.; Kuroyanagi, H.; Tatebayashi, Y.; Hayashi, Y.; Hirabayashi-Takahashi, K.; Saito, K.; Haga, S.; Uemura, T.; Izumi, S. Dual role of the carboxyl-terminal region of pig liver L-kynurenine 3-monooxygenase: Mitochondrial-targeting signal and enzymatic activity. J. Biochem. 2010, 148, 639-650. [CrossRef]

4. Quan, G.X.; Kim, I.; Komoto, N.; Sezutsu, H.; Ote, M.; Shimada, T.; Kanda, T.; Mita, K.; Kobayashi, M.; Tamura, T. Characterization of the kynurenine 3-monooxygenase gene corresponding to the white egg 1 mutant in the silkworm Bombyx mori. Mol. Genet. Genom. 2002, 267, 1-9. [CrossRef] [PubMed]

5. Maddison, D.C.; Alfonso-Nunez, M.; Swaih, A.M.; Breda, C.; Campesan, S.; Allcock, N.; Straatman-Iwanowska, A.; Kyriacou, C.P.; Giorgini, F. A novel role for kynurenine 3-monooxygenase in mitochondrial dynamics. PLoS Genet. 2020, 16, e1009129. [CrossRef] [PubMed]

6. $\quad$ Saito, K.; Quearry, B.J.; Saito, M.; Nowak, T.S., Jr.; Markey, S.P.; Heyes, M.P. Kynurenine 3-hydroxylase in brain: Species activity differences and effect of gerbil cerebral ischemia. Arch Biochem. Biophys 1993, 307, 104-109. [CrossRef]

7. De Castro, F.T.; Brown, R.R.; Price, J.M. The intermediary metabolism of tryptophan by cat and rat tissue preparations. J. Biol. Chem. 1957, 228, 777-784. [CrossRef]

8. Schwarcz, R.; Stone, T.W. The kynurenine pathway and the brain: Challenges, controversies and promises. Neuropharmacology 2017, 112, 237-247. [CrossRef]

9. Schwarcz, R.; Bruno, J.P.; Muchowski, P.J.; Wu, H.Q. Kynurenines in the mammalian brain: When physiology meets pathology. Nat. Rev. Neurosci. 2012, 13, 465-477. [CrossRef]

10. Parrott, J.M.; O'Connor, J.C. Kynurenine 3-monooxygenase: An influential mediator of neuropathology. Front. Psychiatry 2015, 6, 116. [CrossRef]

11. Erhardt, S.; Schwieler, L.; Imbeault, S.; Engberg, G. The kynurenine pathway in schizophrenia and bipolar disorder. Neuropharmacology 2017, 112, 297-306. [CrossRef] [PubMed]

12. Zhang, S.; Collier, M.E.W.; Heyes, D.J.; Giorgini, F.; Scrutton, N.S. Advantages of brain penetrating inhibitors of kynurenine-3monooxygenase for treatment of neurodegenerative diseases. Arch Biochem. Biophys. 2021, 697, 108702. [CrossRef]

13. Alberati-Giani, D.; Ricciardi-Castagnoli, P.; Köhler, C.; Cesura, A.M. Regulation of the kynurenine metabolic pathway by interferon-gamma in murine cloned macrophages and microglial cells. J. Neurochem. 1996, 66, 996-1004. [CrossRef]

14. Guillemin, G.J.; Kerr, S.J.; Smythe, G.A.; Smith, D.G.; Kapoor, V.; Armati, P.J.; Croitoru, J.; Brew, B.J. Kynurenine pathway metabolism in human astrocytes: A paradox for neuronal protection. J. Neurochem. 2001, 78, 842-853. [CrossRef] [PubMed]

15. Giorgini, F.; Möller, T.; Kwan, W.; Zwilling, D.; Wacker, J.L.; Hong, S.; Tsai, L.C.; Cheah, C.S.; Schwarcz, R.; Guidetti, P.; et al. Histone deacetylase inhibition modulates kynurenine pathway activation in yeast, microglia, and mice expressing a mutant huntingtin fragment. J. Biol. Chem. 2008, 283, 7390-7400. [CrossRef] [PubMed]

16. Heyes, M.P.; Saito, K.; Major, E.O.; Milstien, S.; Markey, S.P.; Vickers, J.H. A mechanism of quinolinic acid formation by brain in inflammatory neurological disease. Attenuation of synthesis from L-tryptophan by 6-chlorotryptophan and 4-chloro-3hydroxyanthranilate. Brain 1993, 116, 1425-1450. [CrossRef]

17. Connor, T.J.; Starr, N.; O'Sullivan, J.B.; Harkin, A. Induction of indolamine 2,3-dioxygenase and kynurenine 3-monooxygenase in rat brain following a systemic inflammatory challenge: A role for IFN-gamma? Neurosci. Lett. 2008, 441, 29-34. [CrossRef]

18. Corona, A.W.; Huang, Y.; O'Connor, J.C.; Dantzer, R.; Kelley, K.W.; Popovich, P.G.; Godbout, J.P. Fractalkine receptor (CX3CR1) deficiency sensitizes mice to the behavioral changes induced by lipopolysaccharide. J. Neuroinflamm. 2010, 7, 93. [CrossRef]

19. Garrison, A.M.; Parrott, J.M.; Tunon, A.; Delgado, J.; Redus, L.; O'Connor, J.C. Kynurenine pathway metabolic balance influences microglia activity: Targeting kynurenine monooxygenase to dampen neuroinflammation. Psychoneuroendocrinology 2018, 94, 1-10. [CrossRef]

20. Chiarugi, A.; Cozzi, A.; Ballerini, C.; Massacesi, L.; Moroni, F. Kynurenine 3-mono-oxygenase activity and neurotoxic kynurenine metabolites increase in the spinal cord of rats with experimental allergic encephalomyelitis. Neuroscience 2001, 102, 687-695. [CrossRef]

21. Guillemin, G.J.; Cullen, K.M.; Lim, C.K.; Smythe, G.A.; Garner, B.; Kapoor, V.; Takikawa, O.; Brew, B.J. Characterization of the kynurenine pathway in human neurons. J. Neurosci. 2007, 27, 12884-12892. [CrossRef] [PubMed]

22. Castellano-Gonzalez, G.; Jacobs, K.R.; Don, E.; Cole, N.J.; Adams, S.; Lim, C.K.; Lovejoy, D.B.; Guillemin, G.J. Kynurenine 3-monooxygenase activity in human primary neurons and effect on cellular bioenergetics identifies new neurotoxic mechanisms. Neurotox. Res. 2019, 35, 530-541. [CrossRef] [PubMed] 
23. Laumet, G.; Zhou, W.; Dantzer, R.; Edralin, J.D.; Huo, X.; Budac, D.P.; O'Connor, J.C.; Lee, A.W.; Heijnen, C.J.; Kavelaars, A. Upregulation of neuronal kynurenine 3-monooxygenase mediates depression-like behavior in a mouse model of neuropathic pain. Brain Behav. Immun. 2017, 66, 94-102. [CrossRef] [PubMed]

24. Dagher, N.N.; Najafi, A.R.; Kayala, K.M.; Elmore, M.R.; White, T.E.; Medeiros, R.; West, B.L.; Green, K.N. Colony-stimulating factor 1 receptor inhibition prevents microglial plaque association and improves cognition in 3xTg-AD mice. J Neuroinflamm. 2015, 12, 139. [CrossRef] [PubMed]

25. Spangenberg, E.E.; Lee, R.J.; Najafi, A.R.; Rice, R.A.; Elmore, M.R.; Blurton-Jones, M.; West, B.L.; Green, K.N. Eliminating microglia in Alzheimer's mice prevents neuronal loss without modulating amyloid-beta pathology. Brain 2016, 139, 1265-1281. [CrossRef]

26. Rice, R.A.; Pham, J.; Lee, R.J.; Najafi, A.R.; West, B.L.; Green, K.N. Microglial repopulation resolves inflammation and promotes brain recovery after injury. Glia 2017, 65, 931-944. [CrossRef]

27. Mangiarini, L.; Sathasivam, K.; Seller, M.; Cozens, B.; Harper, A.; Hetherington, C.; Lawton, M.; Trottier, Y.; Lehrach, H.; Davies, S.W.; et al. Exon 1 of the HD gene with an expanded CAG repeat is sufficient to cause a progressive neurological phenotype in transgenic mice. Cell 1996, 87, 493-506. [CrossRef]

28. Paldino, E.; Balducci, C.; La Vitola, P.; Artioli, L.; D'Angelo, V.; Giampa, C.; Artuso, V.; Forloni, G.; Fusco, F.R. Neuroprotective effects of doxycycline in the R6/2 mouse model of Huntington's disease. Mol. Neurobiol. 2020, 57, 1889-1903. [CrossRef]

29. Sathyasaikumar, K.V.; Stachowski, E.K.; Amori, L.; Guidetti, P.; Muchowski, P.J.; Schwarcz, R. Dysfunctional kynurenine pathway metabolism in the R6/2 mouse model of Huntington's disease. J Neurochem. 2010, 113, 1416-1425. [CrossRef]

30. Pellicciari, R.; Natalini, B.; Costantino, G.; Mahmoud, M.R.; Mattoli, L.; Sadeghpour, B.M.; Moroni, F.; Chiarugi, A.; Carpenedo, $\mathrm{R}$. Modulation of the kynurenine pathway in search for new neuroprotective agents. Synthesis and preliminary evaluation of (m-nitrobenzoyl)alanine, a potent inhibitor of kynurenine-3-hydroxylase. J. Med. Chem. 1994, 37, 647-655. [CrossRef]

31. Röver, S.; Cesura, A.M.; Huguenin, P.; Kettler, R.; Szente, A. Synthesis and biochemical evaluation of N-(4-phenylthiazol-2yl)benzenesulfonamides as high-affinity inhibitors of kynurenine 3-hydroxylase. J. Med. Chem. 1997, 40, 4378-4385. [CrossRef] [PubMed]

32. Guidetti, P.; Hoffman, G.E.; Melendez-Ferro, M.; Albuquerque, E.X.; Schwarcz, R. Astrocytic localization of kynurenine aminotransferase II in the rat brain visualized by immunocytochemistry. Glia 2007, 55, 78-92. [CrossRef] [PubMed]

33. Amori, L.; Guidetti, P.; Pellicciari, R.; Kajii, Y.; Schwarcz, R. On the relationship between the two branches of the kynurenine pathway in the rat brain in vivo. J. Neurochem. 2009, 109, 316-325. [CrossRef] [PubMed]

34. Giorgini, F.; Huang, S.Y.; Sathyasaikumar, K.V.; Notarangelo, F.M.; Thomas, M.A.; Tararina, M.; Wu, H.Q.; Schwarcz, R.; Muchowski, P.J. Targeted deletion of kynurenine 3-monooxygenase in mice: A new tool for studying kynurenine pathway metabolism in periphery and brain. J. Biol. Chem. 2013, 288, 36554-36566. [CrossRef] [PubMed]

35. Lavebratt, C.; Olsson, S.; Backlund, L.; Frisen, L.; Sellgren, C.; Priebe, L.; Nikamo, P.; Traskman-Bendz, L.; Cichon, S.; Vawter, M.P.; et al. The KMO allele encoding Arg452 is associated with psychotic features in bipolar disorder type 1, and with increased CSF KYNA level and reduced KMO expression. Mol. Psychiatry 2014, 19, 334-341. [CrossRef]

36. Holt, L.M.; Stoyanof, S.T.; Olsen, M.L. Magnetic cell sorting for in vivo and in vitro astrocyte, neuron, and microglia analysis. Curr. Protoc. Neurosci. 2019, 88, e71. [CrossRef]

37. Berl, S.; Karram, K.; Scheller, A.; Jungblut, M.; Kirchhoff, F.; Waisman, A. Enrichment and isolation of neurons from adult mouse brain for ex vivo analysis. J. Neurosci. Methods. 2017, 283, 15-22. [CrossRef]

38. Lowry, O.H.; Rosebrough, N.J.; Farr, A.L.; Randall, R.J. Protein measurement with the Folin phenol reagent. J. Biol. Chem. 1951, 193, 265-275. [CrossRef]

39. Heyes, M.P.; Saito, K.; Chen, C.Y.; Proescholdt, M.G.; Nowak, T.S., Jr.; Li, J.; Beagles, K.E.; Proescholdt, M.A.; Zito, M.A.; Kawai, K.; et al. Species heterogeneity between gerbils and rats: Quinolinate production by microglia and astrocytes and accumulations in response to ischemic brain injury and systemic immune activation. J. Neurochem. 1997, 69, 1519-1529. [CrossRef]

40. Guillemin, G.J.; Kerr, S.J.; Smythe, G.A.; Armati, P.J.; Brew, B.J. Kynurenine pathway metabolism in human astrocytes. Adv. Exp. Med. Biol. 1999, 467, 125-131. [CrossRef]

41. Colin-Gonzalez, A.L.; Maldonado, P.D.; Santamaria, A. 3-Hydroxykynurenine: An intriguing molecule exerting dual actions in the central nervous system. Neurotoxicology 2013, 34, 189-204. [CrossRef]

42. Sathyasaikumar, K.V.; Tararina, M.; Wu, H.Q.; Neale, S.A.; Weisz, F.; Salt, T.E.; Schwarcz, R. Xanthurenic acid formation from 3-hydroxykynurenine in the mammalian brain: Neurochemical characterization and physiological effects. Neuroscience 2017, 367, 85-97. [CrossRef] [PubMed]

43. Neale, S.A.; Copeland, C.S.; Uebele, V.N.; Thomson, F.J.; Salt, T.E. Modulation of hippocampal synaptic transmission by the kynurenine pathway member xanthurenic acid and other VGLUT inhibitors. Neuropsychopharmacol. Off. Publ. Am. Coll. Neuropsychopharmacol. 2013, 38, 1060-1067. [CrossRef] [PubMed]

44. Fazio, F.; Lionetto, L.; Curto, M.; Iacovelli, L.; Copeland, C.S.; Neale, S.A.; Bruno, V.; Battaglia, G.; Salt, T.E.; Nicoletti, F. Cinnabarinic acid and xanthurenic acid: Two kynurenine metabolites that interact with metabotropic glutamate receptors. Neuropharmacology 2017, 112, 365-372. [CrossRef]

45. Taleb, O.; Maammar, M.; Klein, C.; Maitre, M.; Mensah-Nyagan, A.G. A role for xanthurenic acid in the control of brain dopaminergic activity. Int. J. Mol. Sci. 2021, 22, 6974. [CrossRef] [PubMed] 
46. Chiarugi, A.; Carpenedo, R.; Molina, M.T.; Mattoli, L.; Pellicciari, R.; Moroni, F. Comparison of the neurochemical and behavioral effects resulting from the inhibition of kynurenine hydroxylase and/or kynureninase. J. Neurochem. 1995, 65, 1176-1183. [CrossRef]

47. Wu, H.Q.; Guidetti, P.; Goodman, J.H.; Varasi, M.; Ceresoli-Borroni, G.; Speciale, C.; Scharfman, H.E.; Schwarcz, R. Kynurenergic manipulations influence excitatory synaptic function and excitotoxic vulnerability in the rat hippocampus in vivo. Neuroscience 2000, 97, 243-251. [CrossRef]

48. Erhardt, S.; Öberg, H.; Mathe, J.M.; Engberg, G. Pharmacological elevation of endogenous kynurenic acid levels activates nigral dopamine neurons. Amino Acids 2001, 20, 353-362. [CrossRef]

49. Imbeault, S.; Gubert Olive, M.; Jungholm, O.; Erhardt, S.; Wigstrom, H.; Engberg, G.; Jardemark, K. Blockade of KAT II facilitates LTP in kynurenine 3-monooxygenase depleted mice. Int. J. Tryptophan Res. 2021, 14, 11786469211041368. [CrossRef]

50. Sathyasaikumar, K.V.; Breda, C.; Schwarcz, R.; Giorgini, F. Assessing and modulating kynurenine pathway dynamics in Huntington's disease: Focus on kynurenine 3-monooxygenase. Methods Mol. Biol. 2018, 1780, 397-413. [CrossRef]

51. Dey, S.; Banerjee Dixit, A.; Tripathi, M.; Doddamani, R.S.; Sharma, M.C.; Lalwani, S.; Chandra, P.S.; Banerjee, J. Altered hippocampal kynurenine pathway metabolism contributes to hyperexcitability in human mesial temporal lobe epilepsy-hippocampal sclerosis. Br. J. Pharmacol. 2021, 178, 3959-3976. [CrossRef] [PubMed]

52. Sathyasaikumar, K.V.; Stachowski, E.K.; Wonodi, I.; Roberts, R.C.; Rassoulpour, A.; McMahon, R.P.; Schwarcz, R. Impaired kynurenine pathway metabolism in the prefrontal cortex of individuals with schizophrenia. Schizophr. Bull. 2011, 37, 1147-1156. [CrossRef] [PubMed]

53. Holtze, M.; Saetre, P.; Engberg, G.; Schwieler, L.; Werge, T.; Andreassen, O.A.; Hall, H.; Terenius, L.; Agartz, I.; Jonsson, E.G.; et al. Kynurenine 3-monooxygenase polymorphisms: Relevance for kynurenic acid synthesis in patients with schizophrenia and healthy controls. J. Psychiatry Neurosci. JPN 2012, 37, 53-57. [CrossRef] [PubMed]

54. Oxenkrug, G.; van der Hart, M.; Roeser, J.; Summergrad, P. Peripheral kynurenine-3-monooxygenase deficiency as a potential risk factor for metabolic syndrome in schizophrenia patients. Integr. Clin. Med. 2017, 1, 1-9. [CrossRef] [PubMed]

55. Birner, A.; Platzer, M.; Bengesser, S.A.; Dalkner, N.; Fellendorf, F.T.; Queissner, R.; Pilz, R.; Rauch, P.; Maget, A.; Hamm, C.; et al Increased breakdown of kynurenine towards its neurotoxic branch in bipolar disorder. PLoS ONE 2017, 12, e0172699. [CrossRef] [PubMed]

56. Moroni, F.; Cozzi, A.; Peruginelli, F.; Carpenedo, R.; Pellegrini-Giampietro, D.E. Neuroprotective effects of kynurenine-3hydroxylase inhibitors in models of brain ischemia. Adv. Exp. Med. Biol. 1999, 467, 199-206. [PubMed]

57. Stone, T.W. Kynurenines in the CNS: From endogenous obscurity to therapeutic importance. Prog. Neurobiol. 2001, 64, 185-218. [CrossRef]

58. Schwarcz, R.; Pellicciari, R. Manipulation of brain kynurenines: Glial targets, neuronal effects, and clinical opportunities. J. Pharmacol. Exp. Ther. 2002, 303, 1-10. [CrossRef]

59. Foster, A.C.; Vezzani, A.; French, E.D.; Schwarcz, R. Kynurenic acid blocks neurotoxicity and seizures induced in rats by the related brain metabolite quinolinic acid. Neurosci. Lett. 1984, 48, 273-278. [CrossRef]

60. Guidetti, P.; Schwarcz, R. 3-Hydroxykynurenine potentiates quinolinate but not NMDA toxicity in the rat striatum. Eur. J. Neurosci. 1999, 11, 3857-3863. [CrossRef]

61. Heyes, M.P.; Saito, K.; Crowley, J.S.; Davis, L.E.; Demitrack, M.A.; Der, M.; Dilling, L.A.; Elia, J.; Kruesi, M.J.; Lackner, A.; et al. Quinolinic acid and kynurenine pathway metabolism in inflammatory and non-inflammatory neurological disease. Brain 1992 115, 1249-1273. [CrossRef] [PubMed]

62. Raison, C.L.; Dantzer, R.; Kelley, K.W.; Lawson, M.A.; Woolwine, B.J.; Vogt, G.; Spivey, J.R.; Saito, K.; Miller, A.H. CSF concentrations of brain tryptophan and kynurenines during immune stimulation with IFN-alpha: Relationship to CNS immune responses and depression. Mol. Psychiatry 2010, 15, 393-403. [CrossRef] [PubMed]

63. Kocki, T.; Wnuk, S.; Kloc, R.; Kocki, J.; Owe-Larsson, B.; Urbanska, E.M. New insight into the antidepressants action: Modulation of kynurenine pathway by increasing the kynurenic acid/3-hydroxykynurenine ratio. J. Neural. Transm. 2012, 119, 235-243. [CrossRef] [PubMed]

64. Tashiro, T.; Murakami, Y.; Mouri, A.; Imamura, Y.; Nabeshima, T.; Yamamoto, Y.; Saito, K. Kynurenine 3-monooxygenase is implicated in antidepressants-responsive depressive-like behaviors and monoaminergic dysfunctions. Behav. Brain. Res. 2017, 317, 279-285. [CrossRef]

65. Duda, W.; Curzytek, K.; Kubera, M.; Connor, T.J.; Fagan, E.M.; Basta-Kaim, A.; Trojan, E.; Papp, M.; Gruca, P.; Budziszewska, B.; et al. Interaction of the immune-inflammatory and the kynurenine pathways in rats resistant to antidepressant treatment in model of depression. Int. Immunopharmacol. 2019, 73, 527-538. [CrossRef] [PubMed]

66. Li, C.C.; Jiang, N.; Gan, L.; Zhao, M.J.; Chang, Q.; Liu, X.M.; Pan, R.L. Peripheral and cerebral abnormalities of the tryptophan metabolism in the depression-like rats induced by chronic unpredicted mild stress. Neurochem. Int. 2020, 138, 104771. [CrossRef] [PubMed]

67. Rózsa, E.; Robotka, H.; Vécsei, L.; Toldi, J. The Janus-face kynurenic acid. J. Neural. Transm. 2008, 115, 1087-1091. [CrossRef] [PubMed]

68. Pittaluga, A.; Pattarini, R.; Raiteri, M. Putative cognition enhancers reverse kynurenic acid antagonism at hippocampal NMDA receptors. Eur. J. Pharmacol. 1995, 272, 203-209. [CrossRef] 
69. Chess, A.C.; Simoni, M.K.; Alling, T.E.; Bucci, D.J. Elevations of endogenous kynurenic acid produce spatial working memory deficits. Schizophr. Bull. 2007, 33, 797-804. [CrossRef]

70. Alexander, K.S.; Wu, H.Q.; Schwarcz, R.; Bruno, J.P. Acute elevations of brain kynurenic acid impair cognitive flexibility: Normalization by the alpha7 positive modulator galantamine. Psychopharmacology 2012, 220, 627-637. [CrossRef]

71. Phenis, D.; Vunck, S.A.; Valentini, V.; Arias, H.; Schwarcz, R.; Bruno, J.P. Activation of alpha7 nicotinic and NMDA receptors is necessary for performance in a working memory task. Psychopharmacology 2020, 237, 1723-1735. [CrossRef]

72. Bender, D.A.; McCreanor, G.M. The preferred route of kynurenine metabolism in the rat. Biochim. Biophys. Acta. 1982, 717, 56-60. [CrossRef]

73. Han, Q.; Cai, T.; Tagle, D.A.; Li, J. Structure, expression, and function of kynurenine aminotransferases in human and rodent brains. Cell Mol. Life Sci. 2010, 67, 353-368. [CrossRef] [PubMed]

74. Guidetti, P.; Eastman, C.L.; Schwarcz, R. Metabolism of [5-3H]kynurenine in the rat brain in vivo: Evidence for the existence of a functional kynurenine pathway. J. Neurochem. 1995, 65, 2621-2632. [CrossRef] [PubMed]

75. Heyes, M.P.; Achim, C.L.; Wiley, C.A.; Major, E.O.; Saito, K.; Markey, S.P. Human microglia convert l-tryptophan into the neurotoxin quinolinic acid. Biochem. J. 1996, 320, 595-597. [CrossRef] [PubMed]

76. Speciale, C.; Hares, K.; Schwarcz, R.; Brookes, N. High-affinity uptake of L-kynurenine by a Na+-independent transporter of neutral amino acids in astrocytes. J. Neurosci. 1989, 9, 2066-2072. [CrossRef]

77. Vichaya, E.G.; Malik, S.; Sominsky, L.; Ford, B.G.; Spencer, S.J.; Dantzer, R. Microglia depletion fails to abrogate inflammationinduced sickness in mice and rats. J. Neuroinflammation 2020, 17, 172. [CrossRef] [PubMed]

78. Alberati-Giani, D.; Malherbe, P.; Ricciardi-Castagnoli, P.; Köhler, C.; Denis-Donini, S.; Cesura, A.M. Differential regulation of indoleamine 2,3-dioxygenase expression by nitric oxide and inflammatory mediators in IFN-gamma-activated murine macrophages and microglial cells. J. Immunol. 1997, 159, 419-426. [PubMed]

79. Thomas, S.R.; Mohr, D.; Stocker, R. Nitric oxide inhibits indoleamine 2,3-dioxygenase activity in interferon-gamma primed mononuclear phagocytes. J. Biol. Chem. 1994, 269, 14457-14464. [CrossRef]

80. Speciale, C.; Schwarcz, R. Uptake of kynurenine into rat brain slices. J. Neurochem. 1990, 54, 156-163. [CrossRef]

81. Schwarcz, R.; Du, F.; Schmidt, W.; Turski, W.A.; Gramsbergen, J.B.; Okuno, E.; Roberts, R.C. Kynurenic acid: A potential pathogen in brain disorders. Ann. N. Y. Acad. Sci. 1992, 648, 140-153. [CrossRef]

82. Knyihár-Csillik, E.; Chadaide, Z.; Mihály, A.; Krisztin-Peva, B.; Fenyo, R.; Vécsei, L. Effect of 6-hydroxydopamine treatment on kynurenine aminotransferase-I (KAT-I) immunoreactivity of neurons and glial cells in the rat substantia nigra. Acta Neuropathol. 2006, 112, 127-137. [CrossRef] [PubMed]

83. Formisano, S.; Hornig, M.; Yaddanapudi, K.; Vasishtha, M.; Parsons, L.H.; Briese, T.; Lipkin, W.I.; Williams, B.L. Central nervous system infection with Borna disease virus causes kynurenine pathway dysregulation and neurotoxic quinolinic acid production. J. Virol. 2017, 91, e00673-17. [CrossRef] [PubMed]

84. Balog, E.; Jenei, G.; Gellért, L.; Ono, E.; Vécsei, L.; Toldi, J.; Kis, Z. Species-specific neuronal localization of kynurenine aminotransferase-2 in the mouse cerebellum. Neurochem. Int. 2021, 142, 104920. [CrossRef] [PubMed]

85. Marsh, S.E.; Kamath, T.; Walker, A.; Dissing-Olesen, L.; Hammond, T.R.; De Soysa, T.; Young, A.M.H.; Murphy, S.; Abdulraouf, A.; Nadaf, N.; et al. Dissection of artificial and confounding glial signatures by single cell sequencing of mouse and human brain. In Proceedings of the Neuroscience 2021, Washington, DC, USA, 10 November 2021; Volume P161.01.

86. Wu, H.Q.; Rassoulpour, A.; Schwarcz, R. Kynurenic acid leads, dopamine follows: A new case of volume transmission in the brain? J. Neural. Transm. 2007, 114, 33-41. [CrossRef]

87. Fukuwatari, T. Possibility of amino acid treatment to prevent the psychiatric disorders via modulation of the production of tryptophan metabolite kynurenic acid. Nutrients 2020, 12, 1403. [CrossRef] [PubMed]

88. Wejksza, K.; Rzeski, W.; Okuno, E.; Kandefer-Szerszen, M.; Albrecht, J.; Turski, W.A. Demonstration of kynurenine aminotransferases I and II and characterization of kynurenic acid synthesis in oligodendrocyte cell line (OLN-93). Neurochem. Res. 2005, 30, 963-968. [CrossRef]

89. Owe-Young, R.; Webster, N.L.; Mukhtar, M.; Pomerantz, R.J.; Smythe, G.; Walker, D.; Armati, P.J.; Crowe, S.M.; Brew, B.J. Kynurenine pathway metabolism in human blood-brain-barrier cells: Implications for immune tolerance and neurotoxicity. $J$. Neurochem. 2008, 105, 1346-1357. [CrossRef]

90. Wonodi, I.; Stine, O.C.; Sathyasaikumar, K.V.; Roberts, R.C.; Mitchell, B.D.; Hong, L.E.; Kajii, Y.; Thaker, G.K.; Schwarcz, R. Downregulated kynurenine 3-monooxygenase gene expression and enzyme activity in schizophrenia and genetic association with schizophrenia endophenotypes. Arch. Gen. Psychiatry 2011, 68, 665-674. [CrossRef]

91. Vazquez Cervantes, G.I.; Pineda, B.; Ramirez Ortega, D.; Salazar, A.; Gonzalez Esquivel, D.F.; Rembao, D.; Zavala Vega, S.; Gomez-Manzo, S.; Pérez de la Cruz, G.; Pérez de la Cruz, V. Kynurenine monooxygenase expression and activity in human astrocytomas. Cells 2021, 10, 2028. [CrossRef]

92. Tanizawa, K.; Soda, K. The mechanism of kynurenine hydrolysis catalyzed by kynureninase. J. Biochem. 1979, 86, 1199-1209. [CrossRef]

93. Reyes Ocampo, J.; Lugo Huitrón, R.; Gonzalez-Esquivel, D.; Ugalde-Muniz, P.; Jimenez-Anguiano, A.; Pineda, B.; PedrazaChaverri, J.; Rios, C.; Pérez de la Cruz, V. Kynurenines with neuroactive and redox properties: Relevance to aging and brain diseases. Oxid. Med. Cell Longev. 2014, 2014, 646909. [CrossRef] 
94. Notarangelo, F.M.; Pocivavsek, A. Elevated kynurenine pathway metabolism during neurodevelopment: Implications for brain and behavior. Neuropharmacology 2017, 112, 275-285. [CrossRef]

95. Reszka, K.J.; Bilski, P.; Chignell, C.F.; Dillon, J. Free radical reactions photosensitized by the human lens component, kynurenine: An EPR and spin trapping investigation. Free. Radic. Biol Med. 1996, 20, 23-34. [CrossRef]

96. Ramirez Ortega, D.; Ugalde Muniz, P.E.; Blanco Ayala, T.; Vazquez Cervantes, G.I.; Lugo Huitrón, R.; Pineda, B.; Gonzalez Esquivel, D.F.; Pérez de la Cruz, G.; Pedraza Chaverri, J.; Sanchez Chapul, L.; et al. On the antioxidant properties of L-kynurenine: An efficient ROS scavenger and enhancer of rat brain antioxidant defense. Antioxidants 2021, 11, 31. [CrossRef] [PubMed]

97. Goldstein, L.E.; Leopold, M.C.; Huang, X.; Atwood, C.S.; Saunders, A.J.; Hartshorn, M.; Lim, J.T.; Faget, K.Y.; Muffat, J.A.; Scarpa, R.C.; et al. 3-Hydroxykynurenine and 3-hydroxyanthranilic acid generate hydrogen peroxide and promote alpha-crystallin cross-linking by metal ion reduction. Biochemistry 2000, 39, 7266-7275. [CrossRef] [PubMed]

98. Reyes-Ocampo, J.; Ramirez-Ortega, D.; Cervantes, G.I.; Pineda, B.; Balderas, P.M.; Gonzalez-Esquivel, D.; Sanchez-Chapul, L.; Lugo-Huitrón, R.; Silva-Adaya, D.; Rios, C.; et al. Mitochondrial dysfunction related to cell damage induced by 3hydroxykynurenine and 3-hydroxyanthranilic acid: Non-dependent-effect of early reactive oxygen species production. Neurotoxicology 2015, 50, 81-91. [CrossRef] [PubMed]

99. Coto-Montes, A.; Zsizsik, B.; Hardeland, R. Kynurenic acid-not only an antioxidant: Strong prooxidative interactions between kynurenic and aminolevulinic acids under light exposure. Actions Redox Prop. Melatonin Other Aromat. Amino Acid Metab. 2001, 148-155.

100. Lugo-Huitrón, R.; Blanco-Ayala, T.; Ugalde-Muniz, P.; Carrillo-Mora, P.; Pedraza-Chaverri, J.; Silva-Adaya, D.; Maldonado, P.D.; Torres, I.; Pinzon, E.; Ortiz-Islas, E.; et al. On the antioxidant properties of kynurenic acid: Free radical scavenging activity and inhibition of oxidative stress. Neurotoxicol. Teratol. 2011, 33, 538-547. [CrossRef]

101. Christen, S.; Peterhans, E.; Stocker, R. Antioxidant activities of some tryptophan metabolites: Possible implication for inflammatory diseases. Proc. Natl. Acad. Sci. USA 1990, 87, 2506-2510. [CrossRef]

102. Siska, P.J.; Jiao, J.; Matos, C.; Singer, K.; Berger, R.S.; Dettmer, K.; Oefner, P.J.; Cully, M.D.; Wang, Z.; Quinn, I.W.; et al. Kynurenine induces $\mathrm{T}$ cell fat catabolism and has limited suppressive effects in vivo. EBioMedicine 2021, 74, 103734. [CrossRef]

103. Mandi, Y.; Vécsei, L. The kynurenine system and immunoregulation. J. Neural. Transm. 2012, 119, 197-209. [CrossRef] [PubMed]

104. Minhas, P.S.; Liu, L.; Moon, P.K.; Joshi, A.U.; Dove, C.; Mhatre, S.; Contrepois, K.; Wang, Q.; Lee, B.A.; Coronado, M.; et al. Macrophage de novo $\mathrm{NAD}(+)$ synthesis specifies immune function in aging and inflammation. Nat. Immunol. 2019, 20, 50-63. [CrossRef]

105. Baran, H.; Staniek, K.; Bertignol-Sporr, M.; Attam, M.; Kronsteiner, C.; Kepplinger, B. Effects of various kynurenine metabolites on respiratory parameters of rat brain, liver and heart mitochondria. Int. J. Tryptophan. Res. 2016, 9, 17-29. [CrossRef]

106. Baran, H.; Staniek, K.; Kepplinger, B.; Gille, L.; Stolze, K.; Nohl, H. Kynurenic acid influences the respiratory parameters of rat heart mitochondria. Pharmacology 2001, 62, 119-123. [CrossRef] [PubMed]

107. Robotka, H.; Sas, K.; Agoston, M.; Rozsa, E.; Szenasi, G.; Gigler, G.; Vécsei, L.; Toldi, J. Neuroprotection achieved in the ischaemic rat cortex with L-kynurenine sulphate. Life Sci. 2008, 82, 915-919. [CrossRef]

108. Rentschler, K.M.; Baratta, A.M.; Ditty, A.L.; Wagner, N.T.J.; Wright, C.J.; Milosavljevic, S.; Mong, J.A.; Pocivavsek, A. Prenatal kynurenine elevation elicits sex-dependent changes in sleep and arousal during adulthood: Implications for psychotic disorders. Schizophr. Bull. 2021, 47, 1320-1330. [CrossRef] [PubMed]

109. Savitz, J. The kynurenine pathway: A finger in every pie. Mol. Psychiatry 2020, 25, 131-147. [CrossRef] 